\title{
Green Apple e-Cigarette Flavorant Farnesene Triggers Reward-Related Behavior by Promoting High-Sensitivity nAChRs in the Ventral Tegmental Area
}

\author{
DSkylar Y. Cooper, Austin T. Akers, and ${ }^{\circledR B}$ Brandon J. Henderson
}

https://doi.org/10.1523/ENEURO.0172-20.2020

Department of Biomedical Sciences, Marshall University, Joan C Edwards School of Medicine, Huntington, WV 25703

\begin{abstract}
While combustible cigarette smoking has declined, the use of electronic nicotine delivery systems (ENDS) has increased. ENDS are popular among adolescents, and chemical flavorants are an increasing concern because of the growing use of zero-nicotine flavored e-liquids. Despite this, little is known regarding the effects of ENDS flavorants on vaping-related behavior. Following previous studies demonstrating the green apple flavorant, farnesol, enhances nicotine reward and exhibits rewarding properties without nicotine, this work focuses on the green apple flavorant, farnesene, for its impact on vaping-related behaviors. Using adult C57BL/6J mice, genetically modified to contain fluorescent nicotinic acetylcholine receptors (nAChRs), and farnesene doses of $0.1,1.0$, and $10 \mathrm{mg} / \mathrm{kg}$, we observed farnesene-alone produces reward-related behavior in both male and female mice. We then performed whole-cell patch-clamp electrophysiology and observed farnesene-induced inward currents in ventral tegmental area (VTA) putative dopamine (pDA) neurons that were blocked by the nAChR antagonist, Dh $\beta \mathrm{E}$. While the amplitudes of farnesene-induced currents are $\sim 30 \%$ of nicotine's efficacy, this indicates the potential for some ENDS flavorants to stimulate $\mathrm{nAChR}$ function. Additionally, farnesene enhances nicotine's potency for activating $\mathrm{nAChRs}$ on VTA dopamine neurons. This may be because of changes in nAChR stoichiometry as our data suggest a shift toward high-sensitivity $\alpha 4 \beta 2 \mathrm{nAChRs.} \mathrm{Consequently,} \mathrm{these} \mathrm{data} \mathrm{show} \mathrm{that} \mathrm{the} \mathrm{green} \mathrm{apple} \mathrm{flavorant,} \mathrm{farnesene,}$ causes reward-related behavior without nicotine through changes in nAChR stoichiometry that results in an enhanced effect of nicotine on VTA dopamine neurons. These results demonstrate the importance of future investigations into ENDS flavorants and their effects on vaping-related behaviors.
\end{abstract}

Key words: electrophysiology; flavorants; microscopy; nicotinic receptors; reward-related behavior

\section{Significance Statement}

Although combustible cigarette use has decreased by $\sim 11 \%$ in America over the past two decades, the use of electronic nicotine delivery systems (ENDS) has increased by $135 \%$ and $218 \%$ among high school and middle school students, respectively, in the last two years alone (Cullen et al., 2018, 2019). Because of the fact that most ENDS users vape flavored nicotine products and the growing use of zero-nicotine flavored e-liquids, it raises the questions of how chemical flavorants alter nicotine addiction and if they increase abuse liability themselves. We show that one chemical flavorant and odorant of green apple, farnesene, causes reward-related behavior on its own. These results increase our understanding on how flavorants promote neurologic changes and affect nicotine addiction.

Received April 29, 2020; accepted June 11, 2020; First published August 3, 2020.

The authors declare no competing financial interests.
Author contributions: S.Y.C. and B.J.H. designed research; S.Y.C., A.T.A., and B.J.H. performed research; S.Y.C., A.T.A., and B.J.H. analyzed data; S.Y.C. and B.J.H. wrote the paper. 


\section{Introduction}

Tobacco use remains the leading preventable cause of disease and death in America and results in nearly half a million deaths per year. Although there has been a decline in the use of combustible cigarettes, the use of electronic nicotine delivery systems (ENDS) has increased tremendously with over three million users between the ages of 14 and 18 (Cullen et al., 2018). The former United States Food and Drug Administration (FDA) Commissioner, Scott Gottlieb, stated that he believes the ENDS companies are creating a new demographic market among the youth, rather than simply helping adult smokers quit; which was the original objective for the production of ENDS (FDA, 2018). Since their inception, ENDS have become more of a concern among the adolescent population because of the dramatic increase in use among their age demographic and because of the numerous flavor options available (Cullen et al., 2018; FDA, 2018; Schneller et al., 2018; Mead et al., 2019). Unlike combustible cigarettes which are limited to menthol flavor, there is no restriction on flavored ENDS and currently over 15,000 unique flavors are on the market (Hsu et al., 2018). Additionally, $>90 \%$ of adolescent and $\sim 70 \%$ of adult ENDS users prefer flavored products (Schneller et al., 2018; Mead et al., 2019).

Menthol is the most prominent flavor for tobacco products and was considered to be an inert flavor additive, yet, studies have shown that menthol enhances nicotine reward-related and reinforcement-related behaviors in rodents (Wang et al., 2014; Biswas et al., 2016; Henderson et al., 2017). The menthol-induced enhancement is because of a combination of effects on nicotinic acetylcholine receptor (nAChR) upregulation (Brody et al., 2013; Henderson et al., 2016, 2017), dopamine neuron excitability (Henderson et al., 2018), dopamine release (Zhang et al., 2018), and TrpM8-dependent mechanisms (Fan et al., 2016). In addition to menthol, similar investigations into other popular ENDS flavors are being conducted. A recent report determined that green apple and other fruit flavors are nearly the most popular among all flavorant options available (Espino-Díaz et al., 2016; Omaiye et al., 2019). An investigation into one chemical flavorant of green apple, farnesol, reported that farnesol produced rewardrelated behavior in mice in the absence of nicotine (Avelar et al., 2019). Furthermore, this effect was sex-dependent and was found to be caused by changes in nAChR upregulation and ventral tegmental area (VTA) dopamine neuron firing in males only at the doses examined.

This work was supported by the National Institutes on Drug Abuse (NIDA) at the National Institutes of Health Grant DA040047 (to B.J.H.). Research reported in this publication was supported by NIDA and Food and Drug Administration Center for Tobacco Products Grant DA046335 (to B.J.H.). Funding was also provided by the PhRMA Foundation (Predoctoral Fellowship in Pharmacology/Toxicology to S.Y.C.) and startup funds to B.J.H. by the Marshall University Research Corporation.

Correspondence should be addressed to Brandon J. Henderson at Hendersonbr@marshall.edu.

https://doi.org/10.1523/ENEURO.0172-20.2020 Copyright $@ 2020$ Cooper et al.

This is an open-access article distributed under the terms of the Creative Commons Attribution 4.0 International license, which permits unrestricted use, distribution and reproduction in any medium provided that the original work is properly attributed.
Based on these previous investigations, we have examined another chemical flavorant of green apple, farnesene, to determine its effect on vaping-related behaviors. We used conditioned place preference (CPP) assays to observe farnesene's effect on reward-related behavior, confocal microscopy to observe nAChR changes on midbrain dopamine and GABA neurons associated with the reward pathway, and whole-cell patch-clamp electrophysiology to study changes in midbrain neuron function. These experiments were performed with mice genetically modified to express fluorescently labeled nAChRs and were used in microscopy or electrophysiology following behavioral assays. Following these experiments, we have demonstrated that farnesene enhances nicotine reward-related behavior and prompts reward-related behavior in the absence of nicotine, and thus, may explain the prominence of green apple flavors among ENDS users. Additionally, we identified farnesene acts as a partial agonist for nAChRs and stimulates inward currents on VTA dopamine neurons. Finally, we observed that while farnesene does not exert a pronounced effect on VTA nAChR upregulation, long-term treatment with farnesene alters nAChR stoichiometry to promote the assembly of high-sensitivity nAChRs. Overall, these data identify the significance in studying ENDS flavors and demonstrate the potential underlying mechanisms that may promote the initiation and maintenance of ENDS use among the youth.

\section{Materials and Methods}

\section{Reagents and dose selection}

(-)-Nicotine hydrogen tartrate (product number 1463304) and farnesene (product number W383902-100G-K, lot number MKCB6021) were obtained from Sigma-Aldrich. We determined the relevant dose of farnesene in regard to mouse behavioral assay doses. According to Tierney et al. (2016), flavorants range from 1 - to 20-fold the amount of nicotine in the traditional cigarette as well as ENDS, with an average flavor concentration of $\sim 12 \mathrm{mg} / \mathrm{ml}$ (Omaiye et al., 2019). It has been confirmed that $0.5 \mathrm{mg} /$ $\mathrm{kg}$ nicotine is rewarding for mice in conditioned place preference (CPP) assays (Tapper et al., 2004; Henderson et al., 2016, 2017). Given this dose of nicotine, we determined the clinically relevant dose of farnesene is 0.5$10 \mathrm{mg} / \mathrm{kg}$ and used a dosing range of $0.1,1.0$, and $10 \mathrm{mg} / \mathrm{kg}$ for this study.

\section{Mice}

All experiments were conducted in accordance with the guidelines for care and use of animals provided by the National Institutes of Health. Protocols were approved by the Institutional Animal Care and Use Committee at Marshall University. Mice were group housed on a standard $12 / 12 \mathrm{~h}$ light/dark cycle at $22^{\circ} \mathrm{C}$ and given food and water ad libitum. For all assays, we used $\alpha 4$-mCherry $\alpha 6-$ GFP mice, originated from a C57BL/6J strain that are genetically modified to contain $\alpha 4 *$ and $\alpha 6 *$ nAChR fluorescent tags. These mice have been shown to exhibit similar levels of nAChRs to wild-type mice and behave similar to 


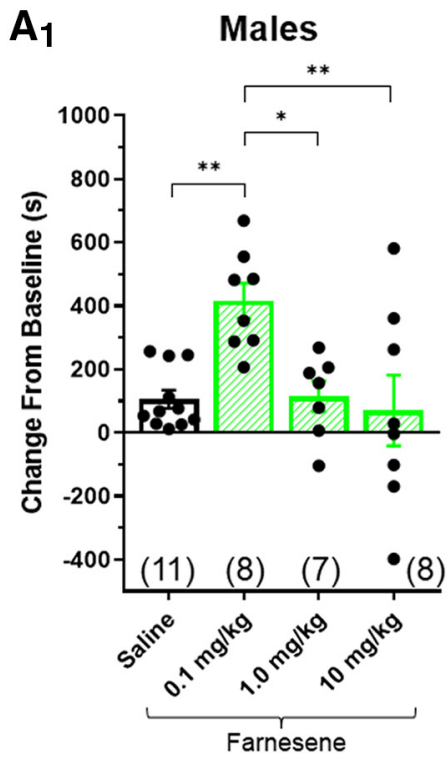

$\mathbf{B}_{1}$

Males

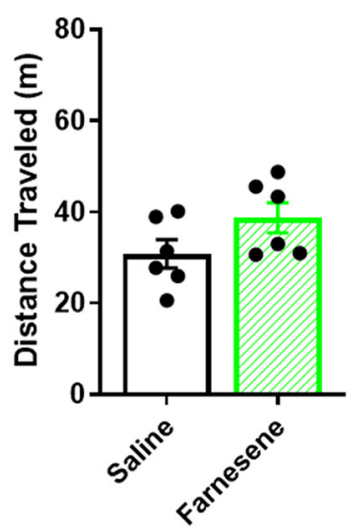

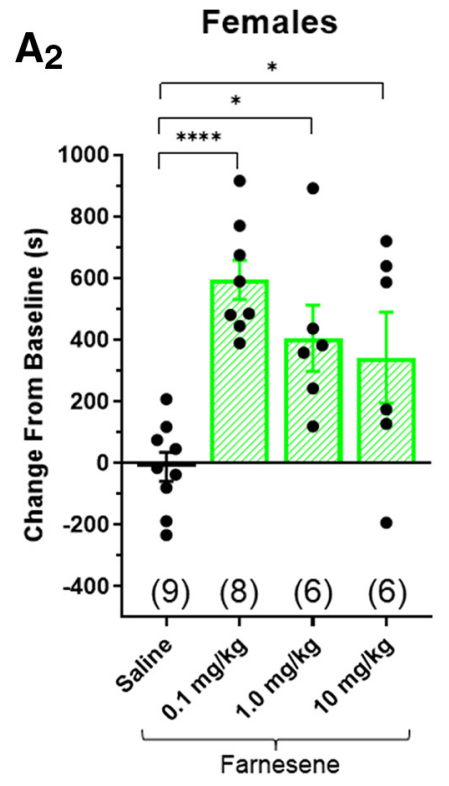

$\mathrm{B}_{2}$

Females

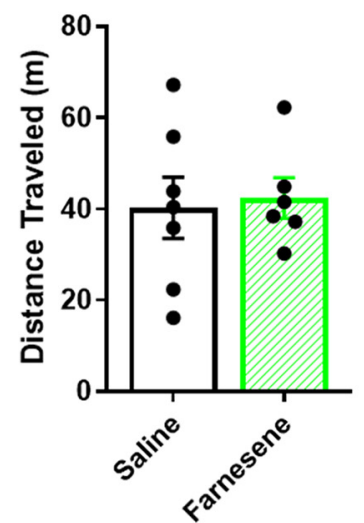

Figure 1. Farnesene-alone produces reward-related behavior in male and female mice. $\boldsymbol{A}_{\mathbf{1 , 2}}$, Male and female mice were administered saline or farnesene at doses of $0.1,1.0$, or $10 \mathrm{mg} / \mathrm{kg}$ in a CPP assay. $\boldsymbol{B}_{\mathbf{1}, 2}$, Male and female mice were administered saline or $0.1 \mathrm{mg} / \mathrm{kg}$ farnesene in an open field locomotor assay. All data are mean \pm SEM; $* p<0.05, * * p<0.01, * * * * p<0.0001$; one-way ANOVA with post hoc Tukey $(\boldsymbol{A})$ or unpaired $t$ test $(\boldsymbol{B})$. Exact $p$ values are given in Results. Number of mice for each treatment group in CPP assays is indicated in parenthesis. Dots within bars represent the CPP scores or locomotor activity from individual mice within the designated treatment groups.

wild-type mice in CPP assays (Mackey et al., 2012; Srinivasan et al., 2016; Henderson et al., 2017; Avelar et al., 2019). Following CPP assays, mouse brains that were homozygous for $\alpha 4$-mCherry and transgenic for $\alpha 6$ GFP were used in confocal microscopy assays $(20$ mice; Fig. 3). For a portion of the behavioral experiments, wild-type littermate mice and The Jackson Laboratory C57BL/6J mice were used alongside $\alpha 4$ mCherry $\alpha 6$-GFP mice. For all experiments, we used adult (three to six months old) mice. Both male and female mice were used and numbers of each are detailed below in the methods for specific experiments and given in detail in corresponding figures.

Our genetically modified $\alpha 4$-mCherry $\alpha 6$-GFP mice were the result of crossing $\alpha 4$-mCherry homozygous knock-in mice (Srinivasan et al., 2016) with $\alpha 6$-GFP bacterial artificial chromosome (BAC) transgenic mice (Mackey et al., 2012). $\alpha 4$-mCherry knock-in mice are backcrossed to C57BL/6J mice every 10 generations while $\alpha 6$-GFP mice are continuously backcrossed to C57BL/6J mice (from The Jackson Laboratory; https:// www.jax.org/strain/000664).

\section{Genotyping}

On postnatal day 21, mice were weaned and housed with same-sex littermates. Concomitantly, tail biopsies were taken for genotyping analysis by PCR (Transnetyx). Only mice that were transgenic for $\alpha 6$-GFP and homozygous for $\alpha 4$-mCherry were used in confocal assays (see below), with the exception of $\alpha 6$-GFP and $\alpha 4$-mCherry mice used for normalized Förster resonance energy transfer (NFRET) controls. 


\section{Locomotor assays}

Adult male and female non-transgenic $\alpha 4$-mCherry $\alpha 6$ GFP mice (three to five months old) were habituated to the experimental room for $\sim 1 \mathrm{~h}$ before the experiment $(n=6-$ $7 \mathrm{mice} / \mathrm{sex})$. Mice were placed in an open field $(40 \times 40 \times$ $36 \mathrm{~cm}$ ) immediately after an intraperitoneal injection of saline or farnesene $(0.1 \mathrm{mg} / \mathrm{kg})$. Distance traveled over a period of $20 \mathrm{~min}$ was recorded using motion tracking software (SMART 3.0). Number of mice are listed in Figure $1 B$.

\section{CPP assays}

CPP assays were conducted in a three-chamber spatial place-preference apparatus (Harvard Apparatus, PanLab) over a 10-d period, using male and female mice (Figures 1 and 2). Time spent in chambers was recorded by motion tracking software (SMART 3.0). The test consisted of three stages: pre-test, injections, post-test. An unbiased protocol was used where "drugs" (saline, nicotine $(0.5 \mathrm{mg} / \mathrm{kg})$, farnesene alone $(0.1,1.0$, or $10 \mathrm{mg} / \mathrm{kg})$, or $0.1 \mathrm{mg} / \mathrm{kg}$ farnesene plus $0.5 \mathrm{mg} / \mathrm{kg}$ nicotine) were given immediately before confinement in the right white/gray chamber on drug days and saline was given immediately before confinement in the left white/black chamber on saline days. Each conditioning period lasted $20 \mathrm{~min}$. Before the use of experimental mice during each stage, a scrap mouse of the same sex was used to deposit odors for $20 \mathrm{~min}$. In the pre-test stage, mice were placed in the central chamber and given 20 min of free access to all chambers. Drug-naive mice that spent $>65 \%$ of their time in one of the two conditioning chambers were removed from the study and the remaining mice were counter-balanced, similar to previously published methods (Neugebauer et al., 2011; Einstein et al., 2013; Lee et al., 2020). Eight males and five females were excluded. During stage 2, intraperitoneal injections were given in the white/gray chamber (saline control, farnesene, nicotine, or farnesene plus nicotine, dissolved in saline) or white/black chamber (saline). The mice received their designated drug injections on days $2,4,6$, and 8 , and received saline injections on days $3,5,7$, and 9 . In the post-test stage, mice were again placed in the central chamber and given $20 \mathrm{~min}$ of free access to all chambers. Adult male and female mice, three to sixmonths old, were used in CPP assays ( 60 males and 57 females total). Previous reports have shown that the use of $\alpha 4-$ mCherry $\alpha 6$-GFP mice have displayed no differences in nicotine reward-related behavior as tested by CPP in comparison to C57BL/6J mice (Henderson et al., 2017; Avelar et al., 2019). Sex differences are further discussed in Results. Data are expressed as a change in baseline preference between the post-test and pre-test. Drug treatments were blind to experimenters until all data analysis was completed.

\section{Confocal imaging of mouse brain slices}

$\alpha 4$-mCherry $\alpha 6$-GFP mice used in CPP assays were also used in microscopy assays. Following the completion of CPP assays, mice were euthanized with $\mathrm{CO}_{2}$ and subjected to a swift cardiac perfusion with 10-ml ice-cold saline to reduce autofluorescence in the mCherry emission range. Brains were then swiftly removed, flash frozen with acetone and dry ice, and then stored at $-80^{\circ} \mathrm{C}$. Brains were coronally sectioned $(20 \mu \mathrm{m})$ using a cryostat, mounted with Vectashield (Vector labs, $\mathrm{H}-1000$ ), and coverslipped. We targeted bregma $-3.1 \mathrm{~mm}$ (anterior-posterior limits of -2.9 to $-3.3 \mathrm{~mm}$ ) because this region gave the most consistent sections that contained a large portion of the VTA, substantia nigra pars reticulata (SNr), and substantia nigra pars compacta (SNc) in a single slice.

A Leica SP5 TCSII confocal microscope was used to excite $\alpha 6$-GFP and $\alpha 4-\mathrm{mCherry}$ at 488 and $561 \mathrm{~nm}$, respectively; $20 \times$ images with a $10 \times$ digital zoom were collected for the quantitative measurements of $\alpha 4$-mCherry and $\alpha 6$-GFP neuron raw integrated density (RID). NFRET was calculated using the PixFRET ImageJ plug-in to identify $\alpha 4 \alpha 6 *$ nAChRs.

All experimenters were blind to drug treatment until all data analysis was completed. Approximately 30-60 VTA dopamine neurons and $\geq 30$ VTA and SNr GABA neurons were imaged. Data from these images were averaged to provide RID values for each mouse. A total of 20 mice were used in confocal assays, aged three to five months ( $n$ provided in Fig. 3).

\section{Neuro-2a cell culture and transient transfections}

Mouse neuroblastoma $2 a$ (neuro-2a) cells were cultured in the following medium: MEM with $5 \%$ fetal bovine serum, $100 \mathrm{IU} / \mathrm{ml}$ penicillin, and $100 \mu \mathrm{g} / \mathrm{ml}$ streptomycin. Cells were plated by adding 90,000 or 50,000 cells (microscopy and electrophysiology, respectively) to poly-D-lysine-coated $35-\mathrm{mm}$ glass-bottom imaging dishes (MatTek Corporation) and cultured in a humidified incubator $\left(37^{\circ} \mathrm{C}, 95 \%\right.$ air, $\left.5 \% \mathrm{CO}_{2}\right)$. Cells were transfected with $500 \mathrm{ng}$ of each $\mathrm{nAChR}$ subunit cDNA plasmid ( $\alpha 4$-mCherry, $\alpha 4$-GFP, and $\beta 2$ wt or $\alpha 4$-mCherry, $\alpha 6$-GFP, and $\beta 2 w t$ depending on intended subtype target and FRET pairing). Following plating procedures, plasmid DNA was mixed with $250 \mu \mathrm{l}$ of Opti-MEM and Lipofectamine-3000 was separately added to the Opti-MEM. After $5 \mathrm{~min}$ at $24^{\circ} \mathrm{C}$, the two solutions were combined and incubated at $24^{\circ} \mathrm{C}$ for $25 \mathrm{~min}$. Plated neuro-2a cells then received the mixed solution and were incubated for $24 \mathrm{~h}$. The next day, Opti-MEM was removed, and the cells received growth medium. 500 nм filter-sterilized farnesene (or sham treatment) was added after replacing the Opti-MEM with standard culture medium. Twenty-four hours after drug/sham addition, neuro-2a cells were imaged on a confocal microscope (discussed above) or examined using electrophysiological methods (discussed below).

\section{Whole-cell patch-clamp electrophysiology}

Using brain slices from three- to five-month-old male and female $\alpha 6$-GFP mice, we identified putative dopamine (pDA) neurons of the VTA for recordings. Dopamine neurons of the lateral VTA selectively express $\alpha 6 *$ nAChRs making our $\alpha 6$-GFP mice suitable for identifying 
pDA neurons in electrophysiological assays. After recent work detailing the presence of $\alpha 6 *$ nAChRs on medial VTA glutamate neurons (Yan et al., 2018), we restricted our recordings to the lateral VTA to increase our chance of accurately identifying pDA neurons. Following behavioral assays, mice were anesthetized with $\mathrm{CO}_{2}$, and then cardiac perfusion was performed using ice-cold NMDGbased artificial CSF (NMDG-ACSF) saturated with 95\% $\mathrm{O}_{2} / 5 \% \mathrm{CO}_{2}$ (carbogen) containing the following: $93 \mathrm{~mm}$ NMDG, $2.5 \mathrm{~mm} \mathrm{KCl,} 1.2 \mathrm{~mm} \mathrm{NaH}_{2} \mathrm{PO}_{4}, 10 \mathrm{~mm} \mathrm{MgSO}_{4}, 0.4$ $\mathrm{mm} \mathrm{CaCl}, 30 \mathrm{~mm} \mathrm{NaHCO}$, $5 \mathrm{~mm}$ Na-ascorbate, $3 \mathrm{~mm}$ Na-pyruvate, $2 \mathrm{~mm}$ thiourea, and $25 \mathrm{~mm}$ glucose. Brains were removed and kept in agarose for slicing with a Compresstome VF-300-OZ (Precisionary Instruments). Coronal brain sections $(250 \mu \mathrm{m})$ were cut into cold carbogenated NMDG-ACSF to obtain slices containing the VTA (target bregma $-3.1 \mathrm{~mm}$; anterior-posterior limits of -2.7 to $-3.5 \mathrm{~mm}$ ) and were then allowed to recover at $32^{\circ} \mathrm{C}$ in carbogenated NMDG-ACSF for $12-15 \mathrm{~min}$. Following this, slices were transferred to standard ACSF containing the following: $125 \mathrm{~mm} \mathrm{NaCl}, 2.5 \mathrm{~mm} \mathrm{KCl}, 1.2 \mathrm{~mm} \mathrm{NaH}_{2} \mathrm{PO}_{4}$, $1.2 \mathrm{mM} \mathrm{MgCl}_{2}$, $2.4 \mathrm{mM} \mathrm{CaCl}_{2}, 26 \mathrm{~mm} \mathrm{NaHCO}_{3}$, and $11 \mathrm{~mm}$ glucose for $1 \mathrm{~h}$ at $32^{\circ} \mathrm{C}$. One hour later, slices were transferred to the recording chamber and continuously perfused with carbogenated ACSF $(1.5-2.0 \mathrm{ml} / \mathrm{min})$ at $32^{\circ} \mathrm{C}$.

Neurons were visualized with an upright microscope (Axio Examiner A1, Zeiss) equipped with an Axiocam 702 mono using DIC near infrared illumination. Blue illumination was used to visualize $\alpha 6$-GFP presence in pDA neurons. Whole-cell patch-clamp techniques were used to record electrophysiological signals with an Integrated Patch-Clamp Amplifier (Sutter). Patch electrodes had resistances of 4-10 M $\Omega$ when filled with intrapipette solution: $135 \mathrm{~mm}$ K gluconate, $5 \mathrm{~mm} \mathrm{KCl,} 5 \mathrm{~mm}$ EGTA, $0.5 \mathrm{~mm}$ $\mathrm{CaCl}_{2}, 10 \mathrm{~mm}$ HEPES, $2 \mathrm{~mm} \mathrm{Mg}-\mathrm{ATP}$, and $0.1 \mathrm{~mm}$ GTP. Recordings were sampled at $\geq 10 \mathrm{kHz}$. The junction potential between patch pipette and bath solutions was nulled just before gigaseal formation. Series resistance was monitored without compensation throughout experiments using SutterPatch software. The recording sessions for neurons were terminated if the series resistance changed by $>20 \%$. Nicotine and farnesene (dissolved in ACSF at pH 7.4) applications were applied using pressure microinjection (Picospritzer III, Parker) at 5 psi. Drug concentrations and duration of applications are given in Results. While microinjections of nicotine mitigate many of the complications of usage in brain slices (diffusion in and out of tissue and cells), we used a maximum of three nicotine puffs per brain slice.

For the recordings of spontaneous EPSCs (sEPSCs), bath perfusion of ACSF was switched to an ACSF solution containing $100 \mu \mathrm{m}$ picrotoxin (Sigma-Aldrich, catalog number 124-87-8) to block $\mathrm{GABA}_{\mathrm{A}}$ receptors. After $5 \mathrm{~min}$, pDA neurons in the VTA were voltage clamped at $-65 \mathrm{mV}$ to record sEPSCs.

For cultured cells, 50,000 neuro-2a cells were plated onto sterilized 12-mm circular glass coverslips, placed in $35-\mathrm{mm}$ culture dishes and cultured in a humidified incubator $\left(37^{\circ} \mathrm{C}, 95 \%\right.$ air, $\left.5 \% \mathrm{CO}_{2}\right)$. Cells were transfected as described above. For patching of neuro-2a cells, we used
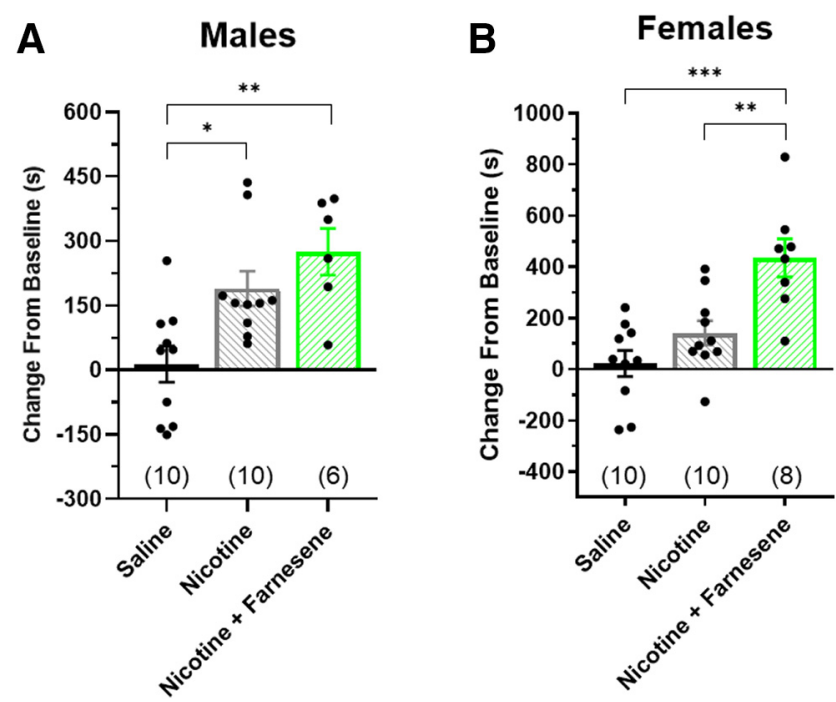

Figure 2. Farnesene $(0.1 \mathrm{mg} / \mathrm{kg})$ enhances nicotine reward-related behavior in both sexes. $\boldsymbol{A}, \boldsymbol{B}$, Male and female mice were administered saline, nicotine $(0.5 \mathrm{mg} / \mathrm{kg})$, or nicotine $(0.5 \mathrm{mg} / \mathrm{kg})$ plus farnesene $(0.1 \mathrm{mg} / \mathrm{kg})$ in a CPP assay. All data are mean \pm SEM; $* p<0.05, * * p<0.01, * * * p<0.005$; one-way ANOVA with post hoc Tukey. Exact $p$ values are given in Results. Number of mice for each treatment group is indicated in parenthesis, and dots within bars represent the CPP scores from individual mice within the designated treatment group.

extracellular solution containing the following: $140 \mathrm{~mm}$ $\mathrm{NaCl}, 5 \mathrm{~mm} \mathrm{KCl}, 2 \mathrm{~mm} \mathrm{CaCl}, 1$ mm $\mathrm{MgCl}_{2}, 10 \mathrm{~mm}$ HEPES, and $10 \mathrm{~mm}$ glucose (320 mOsm, pH set to 7.3 with Trisbase). For voltage-clamp experiments, neuro-2a cells were voltage clamped at a holding potential of $-55 \mathrm{mV}$. To avoid nAChR desensitization by repetitive nicotine application, we applied drug puffs at $\sim 3$-min intervals and continually perfused the recording chamber with extracellular solution.

\section{Statistical analysis}

All results are presented as mean \pm SEM and all statistical analyses were performed using GraphPad Prism. CPP data (Figs. $1 A, 2)$ were analyzed with either a one-way (drug factor) or two-way ANOVA (sex $\times$ drug $\times$ interaction) with a post hoc Tukey for means comparison. Unpaired data (Figs. 1B, 3, 4, 5, 6, 7, 8E $E_{1,2}$ ) were analyzed by $t$ test. Figure $8 B$ was analyzed with a one-way ANOVA (drug factor) with a post hoc Tukey for means comparison. Complete statistical tests and results are displayed in the statistical table provided (Table 1). Power analyses (G*Power software; www.gpower.hhu.de) were used to determine efficient sample sizes (Tables 2-Tables 6).

\section{Results}

\section{Farnesene-alone prompts reward-related behavior}

Here, we examine a chemical flavorant of green apple, farnesene, for its ability to alter reward-related behavior. Using male and female $\alpha 4$-mCherry $\alpha 6$-GFP mice (C57BL/ $6 \mathrm{~J}$ background) and farnesene doses of $0.1,1.0$, and 


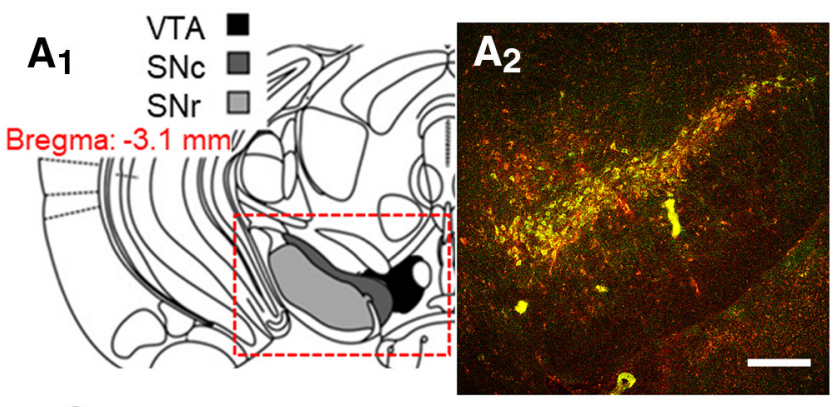

$\mathrm{C}_{1}$

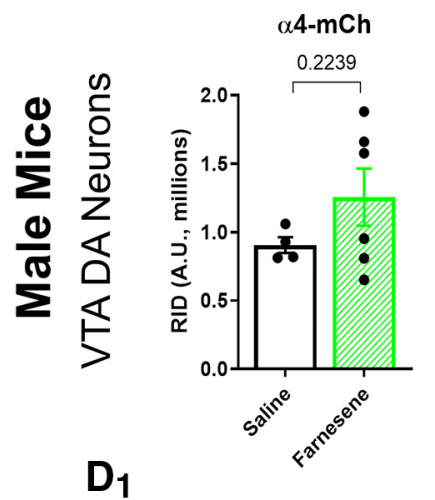

$\alpha 4-\mathrm{mCh}$
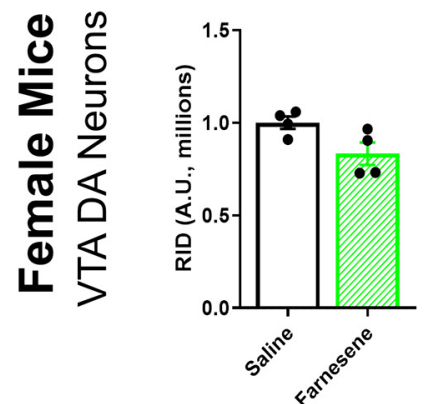

$\alpha$ 6-GFP

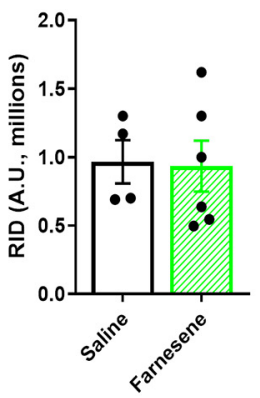

$\alpha 6$-GFP

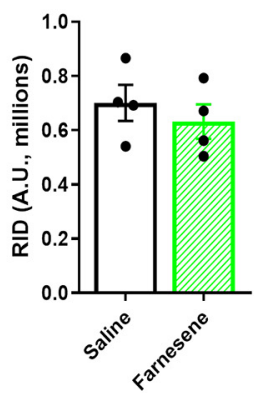

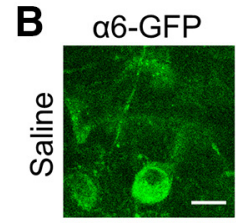
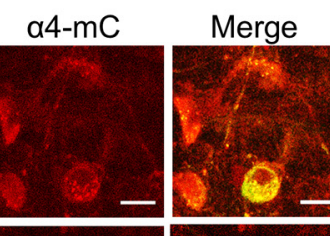

NFRET
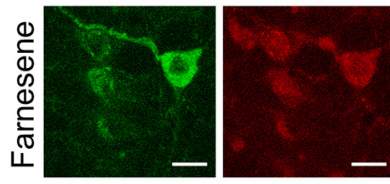

$\mathrm{C}_{2}$
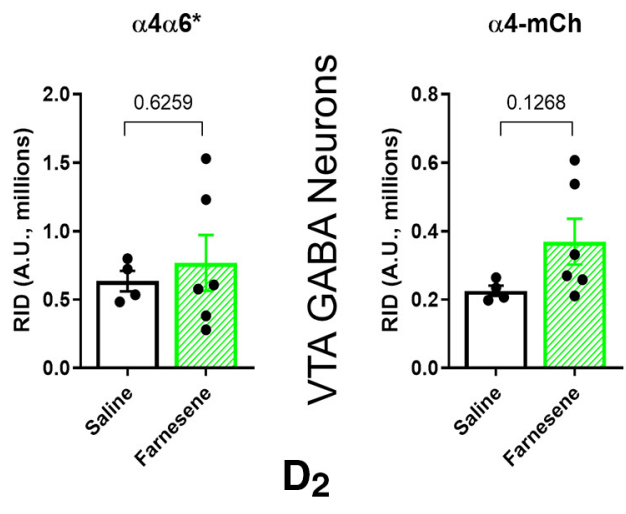

$\mathrm{C}_{3}$
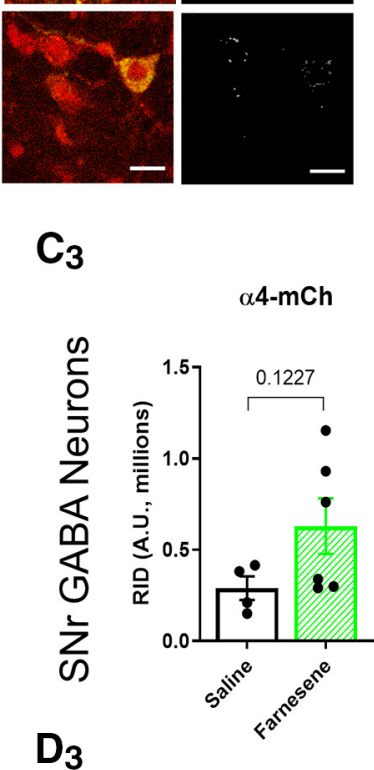

$\alpha 4-m C h$
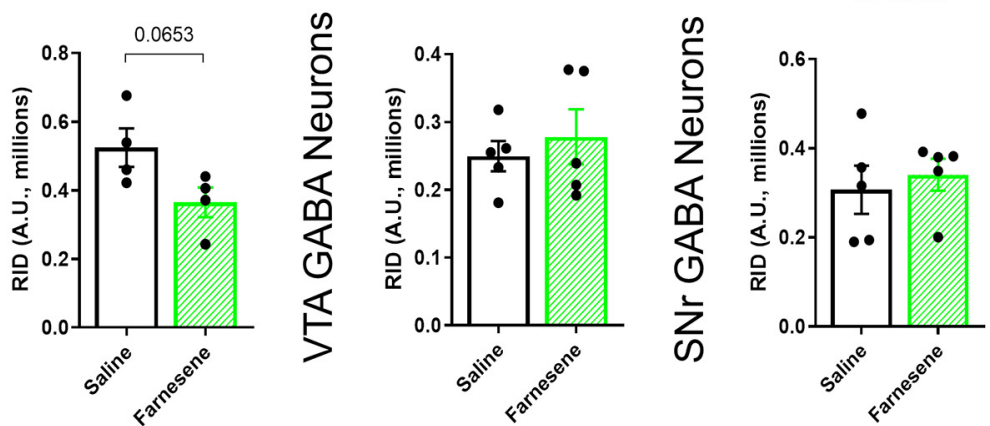

Figure 3. Farnesene treatment has no effect on $\mathrm{nAChR}$ number in the midbrain. $\boldsymbol{A}_{\mathbf{1}}$, Schematic of target mouse brain region (bregma $-3.1 \mathrm{~mm}$ ). $\boldsymbol{A}_{\mathbf{2}}$, Sample $10 \times$ image of a mouse coronal brain section at approximately bregma $-3.1 \mathrm{~mm}$. Scale bar, $250 \mu \mathrm{m}$. $\boldsymbol{B}$, Sample images of saline and farnesene treated VTA dopamine neurons. Scale bar, $15 \mu \mathrm{m}$. C, $\boldsymbol{D}, \mathrm{RID}$ of $\alpha 4 *, \alpha 6 *$, and $\alpha 4 \alpha 6 *$ nAChRs of VTA dopamine neurons $\left(\boldsymbol{C}_{1}, \boldsymbol{D}_{1}\right), \alpha 4 *$ nAChRs of VTA GABA neurons $\left(\boldsymbol{C}_{2}, \boldsymbol{D}_{2}\right)$, and $\alpha 4 *$ nAChRs of SNr GABA neurons $\left(\boldsymbol{C}_{3}, \boldsymbol{D}_{3}\right)$ in saline-treated and farnesene-treated $(0.1 \mathrm{mg} / \mathrm{kg})$ male $(\boldsymbol{C})$ and female $(\boldsymbol{D})$ mice. All data are mean $\pm \mathrm{SEM}$. Unpaired $t$ test. Dots indicate the RID values from individual mice.

$10 \mathrm{mg} / \mathrm{kg}$, we conducted CPP assays to measure rewardrelated behavior. The previous report that examined another green apple flavorant, farnesol, observed a sex-dependent effect on mice in CPP assays (Avelar et al., 2019). Accordingly, we hypothesized that farnesene may produce a sex-dependent effect given the fact that its chemical structure is very similar to farnesol. We observed a sex-dependent and drug-dependent effect in our CPP assays with the above farnesene doses, as well as a significant interaction between sex and drug factors (two-way ANOVA (sex $x$ drug dose $x$ interaction); sex factor: $F_{(1,88)}=10.55, p=0.002$; drug factor: $F_{(5,88)}=12.21, p<0.0001$; and interaction factor: $\left.F_{(5,88)}=3.045, p=0.014\right)$. Following the significant sex-dependent effect, we examined the effect of farnesene on reward-related behavior separately for male and female mice.

We noted a significant effect of farnesene in male and female mice [males: one-way ANOVA, $F_{(3,30)}=5.98$, $p=0.003$ (Fig. $\left.1 A_{1}\right)$; females: one-way ANOVA, $F_{(3,25)}=$ $9.81, p=0.0002$ (Fig. 1 $\left.1 A_{2}\right)$ ]. In males, farnesene at a dose of $0.1 \mathrm{mg} / \mathrm{kg}$ prompted a significant rewarding effect compared with saline-treated $(p=0.0065), 1.0 \mathrm{mg} / \mathrm{kg}$ farnesene-treated $(p=0.020)$, and $10 \mathrm{mg} / \mathrm{kg}$ farnesenetreated $(p=0.005)$ mice. Higher doses of farnesene in male mice did not exhibit a significant change from baseline compared with saline, which may mimic nicotine's inverted-U dose response in CPP assays. On the other 

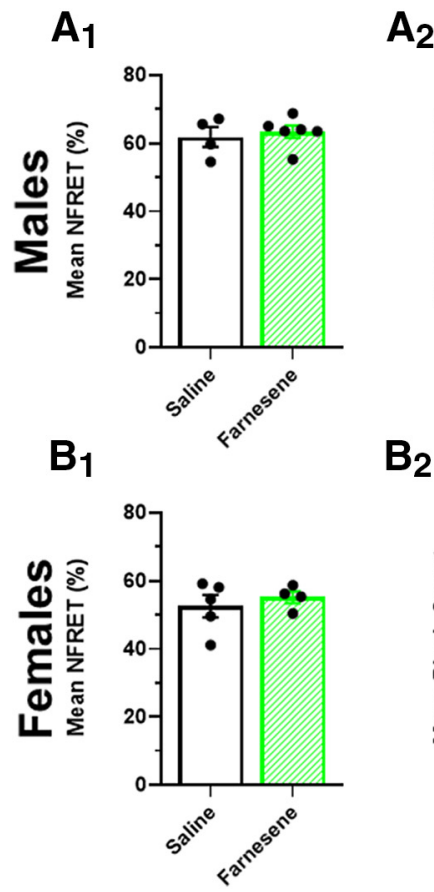

$\mathrm{B}_{2}$
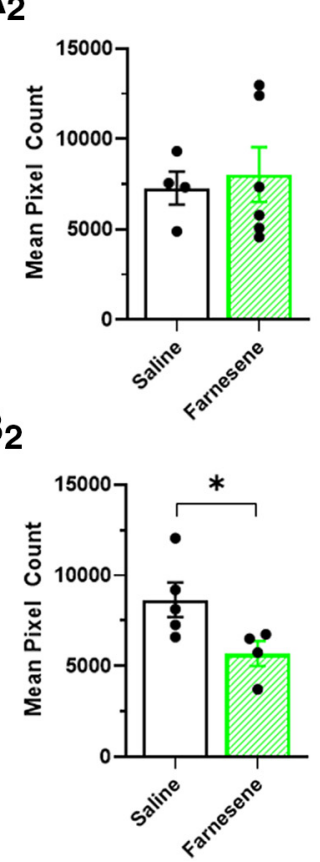

$\mathrm{A}_{3}$

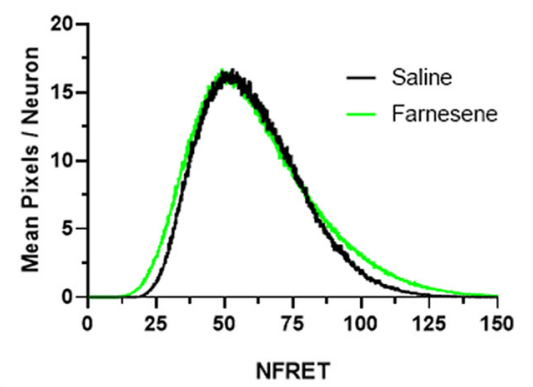

$B_{3}$

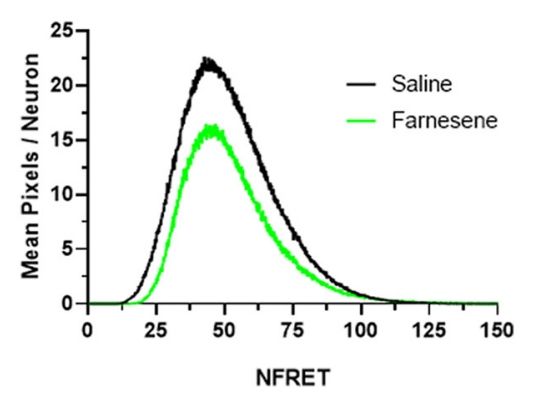

Figure 4. Farnesene alters the stoichiometry of $\alpha 4 \alpha 6 \beta 2 *$ nAChRs in VTA DA neurons. Mean NFRET percentage $\left(\boldsymbol{A}_{\mathbf{1}}, \boldsymbol{B}_{\mathbf{1}}\right)$, mean NFRET pixel count $\left(\boldsymbol{A}_{\mathbf{2}}, \boldsymbol{B}_{2}\right)$, and mean pixels/neuron histograms $\left(\boldsymbol{A}_{\boldsymbol{3}}, \boldsymbol{B}_{3}\right)$ for saline-treated and farnesene-treated $(0.1 \mathrm{mg} / \mathrm{kg}) \mathrm{VTA}$ dopamine neurons in male $(\boldsymbol{A})$ and female $(\boldsymbol{B})$ mice. All data are mean $\pm \mathrm{SEM} ; * p<0.05$; unpaired $t$ test. Exact $p$ values are given in Results. Dots within bars represent the values from individual mice within the designated treatment group; $n>40$ neurons per mouse per treatment group.
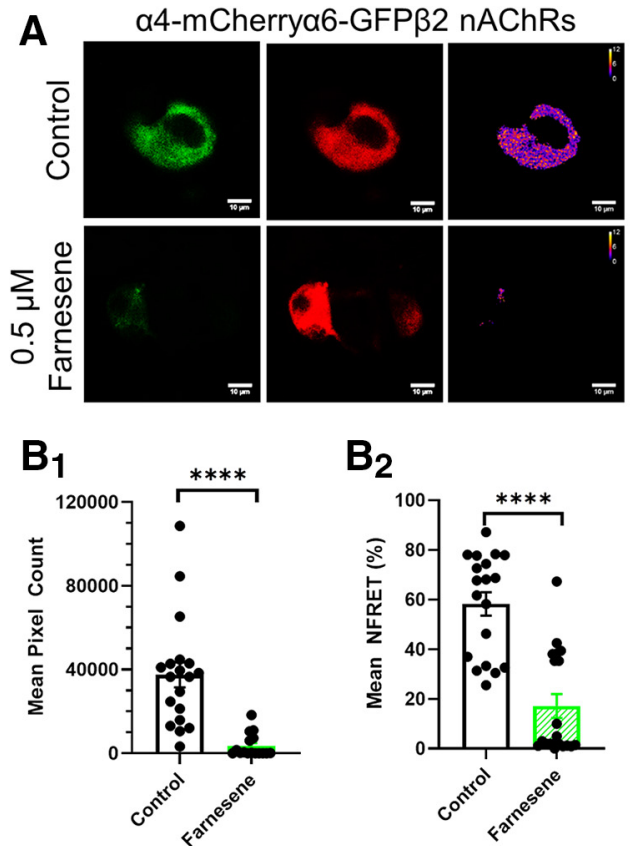

$\mathbf{B}_{2}$

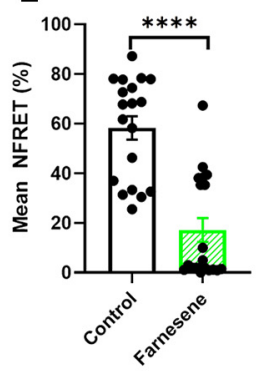

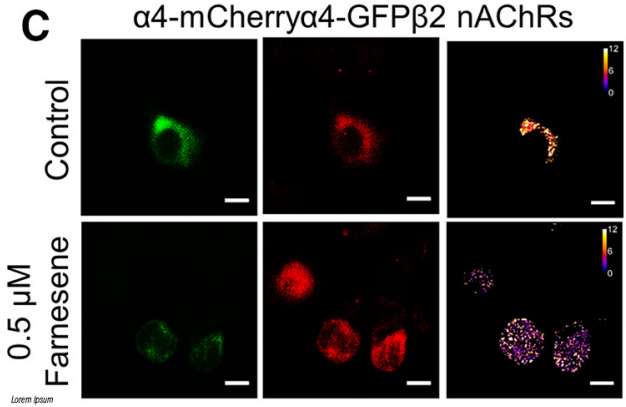

$\mathrm{D}_{1}$

$\mathrm{D}_{2}$

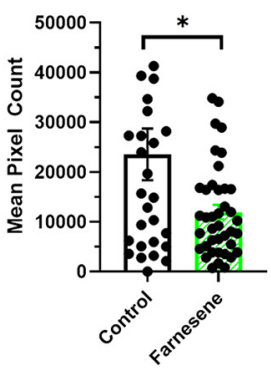

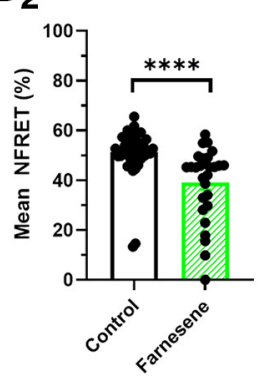

Figure 5. Farnesene favors high-sensitivity nAChRs in neuro-2a cells. Representative neuro-2a cells transfected with $\alpha 4-\mathrm{mCherry}$, $\alpha 4$-GFP or $\alpha 6$-GFP, and $\beta 2$ wt nAChR subunits to produce $(\boldsymbol{A}) \alpha 4$-mCherry $\alpha 6$-GFP $\beta 2 \mathrm{nAChRs}$ or $(\boldsymbol{C}) \alpha 4$-mCherry $\alpha 4$-GFP $\beta 2$ nAChRs. Scale bar, $10 \mu \mathrm{m}$. Mean NFRET pixel count $\left(\boldsymbol{B}_{\mathbf{1}}, \boldsymbol{D}_{\mathbf{1}}\right)$ and NFRET percentage $\left(\boldsymbol{B}_{2}, \boldsymbol{D}_{2}\right)$ treated as control or with $0.5 \mu \mathrm{m}$ farnesene for $(\boldsymbol{A}) \alpha 4$-mCherry $\alpha 6$-GFP $\beta 2$ nAChRs or (C) $\alpha 4$-mCherry $\alpha 4$-GFP $\beta 2$ nAChRs. All data are mean \pm SEM; $* p<0.05$, $* * * * p<0.001$; unpaired $t$ test. Exact $p$ values are given in Results. Dots within bars represent the values from individual cells within the designated treatment group; $n>30$ cells per condition. 
Table 1: Statistical tests and results

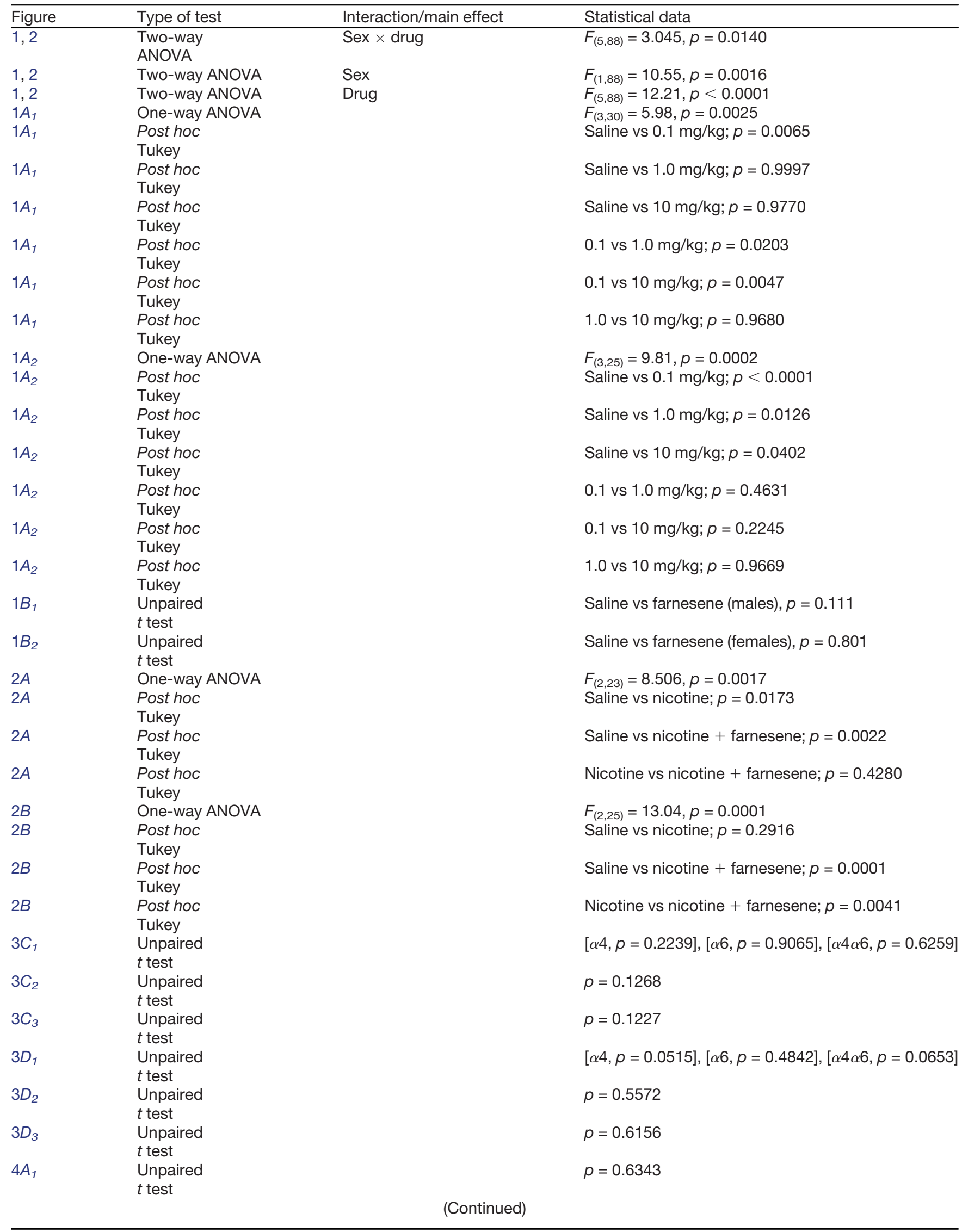


Table 1: Continued

\begin{tabular}{|c|c|c|c|}
\hline Figure & Type of test & Interaction/main effect & Statistical data \\
\hline$\overline{4 A_{2}}$ & $\begin{array}{l}\text { Unpaired } \\
t \text { test }\end{array}$ & & $p=0.7225$ \\
\hline $4 B_{1}$ & $\begin{array}{l}\text { Unpaired } \\
t \text { test }\end{array}$ & & $p=0.5285$ \\
\hline $4 B_{2}$ & $\begin{array}{l}\text { Unpaired } \\
t \text { test }\end{array}$ & & $p=0.0480$ \\
\hline $5 B_{1}$ & $\begin{array}{l}\text { Unpaired } \\
t \text { test }\end{array}$ & & $p<0.0001$ \\
\hline $5 B_{2}$ & $\begin{array}{l}\text { Unpaired } \\
t \text { test }\end{array}$ & & $p<0.0001$ \\
\hline $5 D_{1}$ & $\begin{array}{l}\text { Unpaired } \\
t \text { test }\end{array}$ & & $p=0.0149$ \\
\hline $5 D_{2}$ & $\begin{array}{l}\text { Unpaired } \\
t \text { test }\end{array}$ & & $p<0.0001$ \\
\hline $7 E_{1}$ & $\begin{array}{l}\text { Unpaired } \\
t \text { test }\end{array}$ & & $p=0.0002$ \\
\hline $7 E_{2}$ & $\begin{array}{l}\text { Unpaired } \\
t \text { test }\end{array}$ & & $p<0.0001$ \\
\hline $8 B$ & One-way ANOVA & & $F_{(2,12)}=23.05, p<0.0001$ \\
\hline $8 B$ & $\begin{array}{l}\text { Post hoc } \\
\text { Tukey }\end{array}$ & & $5 \mu \mathrm{M}$ farnesene vs $500 \mu \mathrm{M}$ farnesene; $p=0.1823$ \\
\hline $8 B$ & $\begin{array}{l}\text { Post hoc } \\
\text { Tukey }\end{array}$ & & $5 \mu \mathrm{M}$ farnesene vs $100 \mu \mathrm{M}$ nicotine; $p<0.0001$ \\
\hline $8 B$ & $\begin{array}{l}\text { Post hoc } \\
\text { Tukey }\end{array}$ & & $500 \mu \mathrm{M}$ farnesene vs $100 \mu \mathrm{M}$ nicotine, $p=0.0031$ \\
\hline $8 E_{1}$ & $\begin{array}{l}\text { Unpaired } \\
t \text { test }\end{array}$ & & $p<0.0001$ \\
\hline $8 E_{2}$ & $\begin{array}{l}\text { Unpaired } \\
t \text { test }\end{array}$ & & $p<0.0001$ \\
\hline
\end{tabular}

hand, female mice exhibited a significant change from baseline with all farnesene doses when compared with saline $(1.0 \mathrm{mg} / \mathrm{kg}, p=0.013 ; 10 \mathrm{mg} / \mathrm{kg}, p=0.040 ;$ Fig. $\left.1 A_{2}\right)$, with the greatest change from baseline at $0.1 \mathrm{mg} / \mathrm{kg}$ $\left(p<0.0001\right.$; Fig. 1 $\left.A_{2}\right)$. We note, farnesene doses tested may need to be higher in order for the females to observe an inverted-U response similar to the males. Similarly, we may need to test lower doses in both males and females to determine the threshold dose for reward-related behavior. Overall, these data support the idea that farnesene at $0.1 \mathrm{mg} / \mathrm{kg}$ is rewarding on its own in both male and female mice. Following these observations, follow-up assays were performed with $0.1 \mathrm{mg} / \mathrm{kg}$ dosing in male and female mice.

Additionally, we conducted locomotor assays to determine the effects of acute farnesene treatment on locomotor behavior in male and female mice. It is well understood that nicotine increases locomotor activity in mice (Wall et al., 2017), and was recently determined that green apple flavorant, farnesol, also increased this behavior (Avelar et al., 2019). Here, male and female mice were administered intraperitoneal injections of saline or $0.1 \mathrm{mg} / \mathrm{kg}$ farnesene, and locomotor activity was assessed in an open field test $\left(\right.$ Fig. $\left.1 B_{1,2}\right)$. Unlike the previous reports, farnesene did not significantly alter the ambulatory behavior of either male or female mice compared with saline treatment [males, $p<0.111$ (Fig. $1 B_{1}$ ); females, $p<0.801$ (Fig. 1 $\left.B_{2}\right)$ ].

\section{Farnesene enhances nicotine reward}

Because of the fact that many ENDS users prefer flavored nicotine-containing products, and the findings that farnesene-alone is rewarding (Fig. 1A), it is important we study the combining effect of farnesene and nicotine on reward-related behavior. To do so, we performed

Table 2: G*Power statistics, CPP (Figs. 1, 2)

\begin{tabular}{|c|c|c|c|}
\hline \multicolumn{2}{|c|}{ Input parameters } & \multicolumn{2}{|c|}{ Output parameters } \\
\hline Test family & $F$ tests & Noncentrality parameter & 16.94 \\
\hline Test type & ANOVA: one-way & Critical F & 2.21 \\
\hline Type of analysis & A priori & Numerator df & 7 \\
\hline Effect size & 0.55 & Denominator df & 48 \\
\hline$\alpha$ err prob & 0.05 & Total sample size & 56 \\
\hline Power & 0.8 & Sample size/group & 7 \\
\hline Number of groups & 8 & Actual Power & 0.811 \\
\hline
\end{tabular}

Sample size indicates number of mice needed per treatment group. 
Table 3: G*Power statistics, locomotor behavior (Fig. 1B 1,2 )

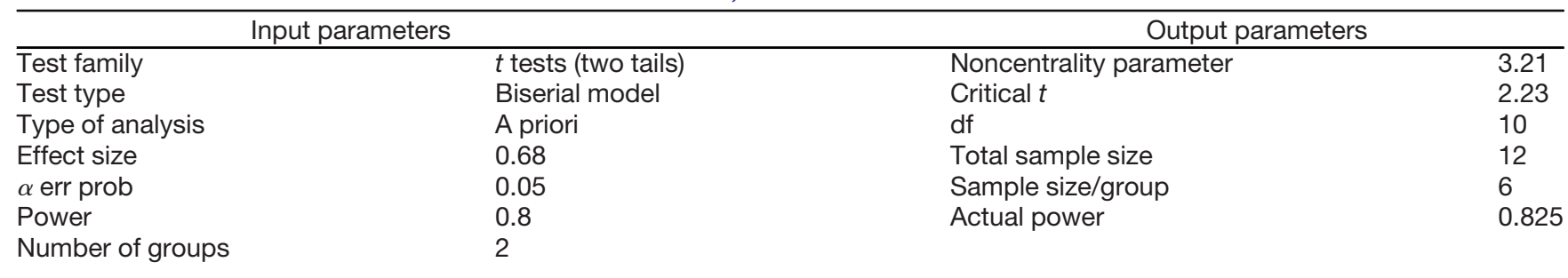

Sample size indicates the number of neurons/cells needed for sufficient power.

additional CPP assays using saline, nicotine, and nicotine combined with the peak farnesene dose $(0.1 \mathrm{mg} /$ $\mathrm{kg}$ ). Many previous reports have used $0.5 \mathrm{mg} / \mathrm{kg}$ nicotine (intraperitoneal) to produce a rewarding effect in C57 mice (Tapper et al., 2004). Accordingly, we selected this dose for these CPP assays. Only male mice exhibited significant nicotine reward-related behavior (one-way ANOVA, $p=0.017$ and $p=0.292$ for males and females, respectively; Fig. $2 A, B$ ); however, in both sexes, we noted a significant nicotine + farnesene effect compared with saline [one-way ANOVA; males, $p=0.002$ (Fig. 2A); females, $p=0.0001$ (Fig. 2B)]. Additionally, both sexes exhibited enhanced rewarding effects in the nicotine + farnesene group compared with nicotine alone, but only females exhibited a significant enhancement $(p=0.004)$.

\section{Despite effects on reward-related behavior, farnesene does not upregulate nAChRs on VTA dopamine neurons}

Following behavioral assays, we performed confocal microscopy to observe potential changes in nAChR levels based on the long-standing knowledge that chronic nicotine exposure upregulates nAChRs (Nashmi et al., 2003, 2007; Henderson et al., 2014; Srinivasan et al., 2016) and that green apple flavorant, farnesol, worked in a similar manner (Avelar et al., 2019). Following the well-characterized effects of $n A C h R$ upregulation in midbrain neurons, we focused on dopamine and GABA neurons in the VTA and GABAergic neurons in the $\mathrm{SNr}$ (Fig. $3 A$ ). Using $\alpha 4$-mCherry $\alpha 6$-GFP mice, we examined $\alpha 4 \beta 2 *$ (* denotes other subunits may be present), $\alpha 6 \beta 2 *$, and $\alpha 4 \alpha 6 \beta 2 * \mathrm{nAChR}$ density of $\mathrm{pDA}$ and GABA neurons in the VTA and SNr in response to saline or farnesene treatment. Here, we used the same mice that were employed in CPP assays to maintain dosing relevant to reward-related behavior. To aid in the identification of pDA neurons in the VTA, we used $\alpha 6$-GFP fluorescence as a marker, as $\alpha 6$-GFP nAChR subunits are highly expressed in dopamine neurons in the lateral VTA (Mackey et al., 2012; described further in methods for electrophysiology). Given that GFP and mCherry are FRET pairings, we used pixelbased FRET methods to identify nAChRs that contain both $\alpha 4$ and $\alpha 6 \mathrm{nAChR}$ subunits (Fig. $3 B$ ). Changes in $\mathrm{nAChR}$ number was determined by quantifying a change in RID of $\alpha 4$-mCherry or $\alpha 6$-GFP fluorescence. Unlike the previous study by Avelar et al. (2019), demonstrating farnesol's ability to upregulate nAChRs (2019), farnesene treatment produced no significant changes in $\mathrm{nAChR}$ number within $\mathrm{pDA}$ or GABA neurons in the VTA or SNr (Fig. 3C,D).

\section{Despite the absence of upregulation, farnesene alters stoichiometry of nAChRs}

In addition to examining the upregulation of nAChRs in mouse brain slices, we also investigated farnesene-induced changes in nAChR stoichiometry. Nicotine has long been known to selectively upregulate high-sensitivity nAChRs, including $\alpha 4 *$ and $\alpha 6 *$ nAChRs (Kuryatov et al., 2005; Srinivasan et al., 2011), while menthol (in the absence of nicotine) and cytisine have been shown to upregulate low-sensitivity nAChRs (Srinivasan et al., 2012; Henderson et al., 2016). $\alpha 4 \beta 2 \mathrm{nAChRs}$ exist in two stoichiometries: high sensitivity $\left(\alpha 4_{(2)} \beta 2_{(3)}\right)$ and low sensitivity $\left(\alpha 4_{(3)} \beta 2_{(2)}\right.$; Nelson et al., 2003). $\alpha 6 *$ nAChR stoichiometries are characterized as $\alpha 6 \beta 2, \alpha 6 \beta 2 \beta 3$, or $\alpha 4 \alpha 6 \beta 2 \beta 3$ (Lindstrom et al., 1987; Xiao et al., 2011; Henderson et al., 2014).

To determine farnesene's effects on nAChR stoichiometry, we used a pixel-based, NFRET method (Srinivasan et al., 2012). Aside from quantifying the RID of $\alpha 4 *, \alpha 6 *$, and $\alpha 4 \alpha 6 *$ nAChRs, we additionally examined the effect of farnesene treatment on NFRET intensity and pixel count as both are informative measurements regarding the change in number of nAChR pentamers that contain both an $\alpha 4$ and $\alpha 6$ nAChR subunit (Fig. 4). In both males

Table 4: G*Power statistics, fluorescence microscopy (Figs. 3, 4)

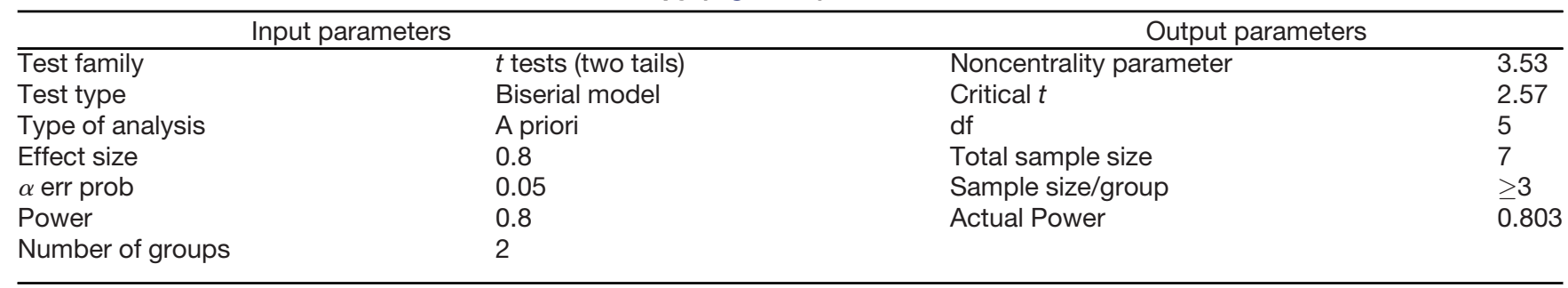

Sample size indicates number of mice needed per treatment group. 
Table 5: G*Power statistics, brain slice electrophysiology (sEPSCs; Fig. 7)

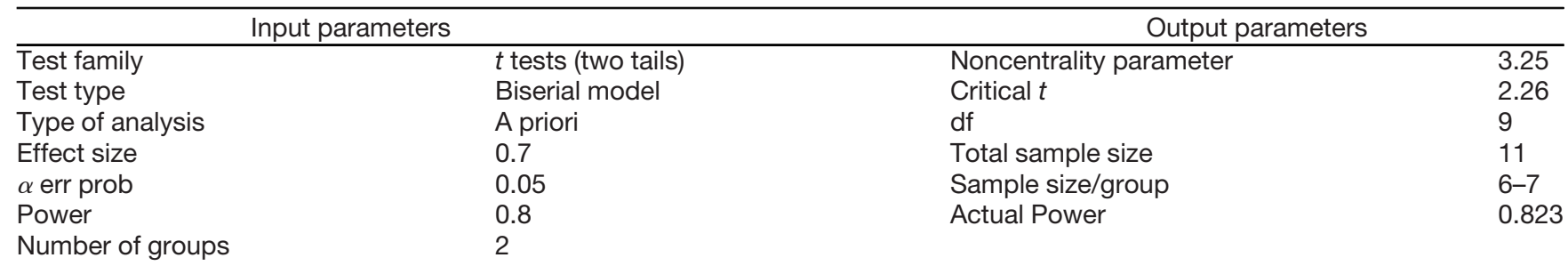

Sample size indicates the number of neurons needed for sufficient power.

and females, we saw no significant changes in the mean NFRET intensity between saline and farnesene treatment groups (Fig. $4 A_{1}, B_{1}$ ). Yet, in females-only, we observed a significant decrease in the mean pixel count following farnesene treatment $(p=0.048$; Fig. 4B2,3). This indicates that farnesene reduces the number of $\alpha 4 \alpha 6 * \mathrm{nAChRs}$ on VTA dopamine neurons in female mice. Given that females demonstrated the greatest range in farnesene-induced reward-related behavior, this finding may explain why we only see an effect on pixel count in female mice.

Given that our mouse model only allows analysis of changes in $\alpha 4 \alpha 6 *$ nAChR stoichiometry, we used in vitro methods to examine both $\alpha 4 \alpha 6 \beta 2$ and $\alpha 4 \beta 2$ nAChR stoichiometry following farnesene exposure. Accordingly, we studied nAChR stoichiometry changes using neuro-2a cells that were transiently transfected with $\alpha 4$-mCherry, $\alpha 6$-GFP, and $\beta 2$ wt or $\alpha 4$-mCherry, $\alpha 4$-GFP, and $\beta 2 w t$ nAChR subunits to examine changes in $\alpha 4 \alpha 6 \beta 2$ and $\alpha 4 \beta 2$ nAChR stoichiometry (Fig. 5A,C, respectively). Cells transiently transfected to contain $\alpha 4$-mCherry $\alpha 6$ GFP $\beta 2$ nAChRs (Fig. $5 A$ ) were treated with control media or $0.5 \mu \mathrm{M}$ farnesene for $24 \mathrm{~h}$. We selected $0.5 \mu \mathrm{M}$ farnesene to match previous studies with the similarly structured terpene, menthol (Henderson et al., 2016) and farnesol (Avelar et al., 2019). In farnesene-treated cells, we noted a significant decrease in the mean pixel count $\left(p<0.0001\right.$; Fig. $\left.5 B_{1}\right)$ and the mean NFRET percentage $\left(p<0.0001\right.$; Fig. $\left.5 B_{2}\right)$, which indicates a significant decrease in the number of $\alpha 4-\alpha 6$ nAChR subunit pairings. Thus, the data obtained with in vitro methods matches those obtained using mouse brain slices. Cells transiently transfected to contain $\alpha 4$-mCherry $\alpha 4$-GFP $\beta 2$ nAChRs (Fig. 5C) were also treated with control media or $0.5 \mu \mathrm{M}$ farnesene, and we also observed a significant decrease in mean pixel count ( $p=0.0149$; Fig. $\left.5 D_{1}\right)$ and mean NFRET percentage $\left(p<0.0001\right.$; Fig. $\left.5 D_{2}\right)$. Accordingly, this indicates a decrease in the number of low-sensitivity $\alpha 4_{(3)} \beta 2_{(2)} \mathrm{nAChRs}$. These results are further summarized in Figure 6. Here, we show that long-term farnesene treatment promotes the inclusion of high-sensitivity nAChRs by transitioning the number of low-sensitivity $\alpha 4_{(3)} \beta 2_{(2)}$ (Fig. 6A) and $\alpha 4 \alpha 6 \beta 2$ (Fig. 6B) $\mathrm{nAChRs}$ to a majority of high-sensitivity $\alpha 4_{(2)} \beta 2_{(3)}$ nAChRs.

\section{Farnesene alters VTA dopamine neuron function}

Although we found no significant changes in nAChR upregulation or downregulation on VTA neurons, the changes in stoichiometry observed in VTA dopamine neurons and neuro-2a cells suggest farnesene alters stoichiometry, potentially toward high-sensitivity $\alpha 4 \beta 2 \mathrm{nAChRs}$. To examine this in an in vivo model, we used brain slice whole-cell electrophysiology. Given that high-sensitivity and low-sensitivity $\alpha 4 \beta 2 *$ nAChRs can be functionally distinguished through concentration-response relationships (Nelson et al., 2003; Xiao et al., 2009), we used similar methods to determine whether farnesene treatment altered nAChR stoichiometry on putative VTA dopamine neurons. Mackey et al. (2012) have previously demonstrated $\alpha 6 \mathrm{nAChRs}$ exhibit complete overlap with tyrosine hydroxylase in VTA dopamine neurons. Thus, several previous investigations have used $\alpha 6$-GFP fluorescence, in addition to other electrophysiological markers, as a method to identify dopamine neurons within the VTA and SNc (Mackey et al., 2012; Henderson et al., 2016, 2017; Avelar et al., 2019). However, more recent investigations have shown that $\alpha 6$ GFP nAChRs are present on glutamate neurons in the medial portions of the VTA (Yan et al., 2018). To increase our chances of identifying pDA neurons, we targeted $\alpha 6$-GFP positive cells (Fig. $7 A_{1,2}$ ) in the lateral VTA that exhibited classical electrophysiological markers of dopamine neurons (Margolis et al., 2006, 2008): hyperpolarizing sag $\left(I_{\mathrm{h}}\right)$, firing frequency, and action potential widths $>2 \mathrm{~ms}$. Together, these features have been proven to provide a

Table 6: G*Power statistics, electrophysiology (inward currents; Fig. 8)

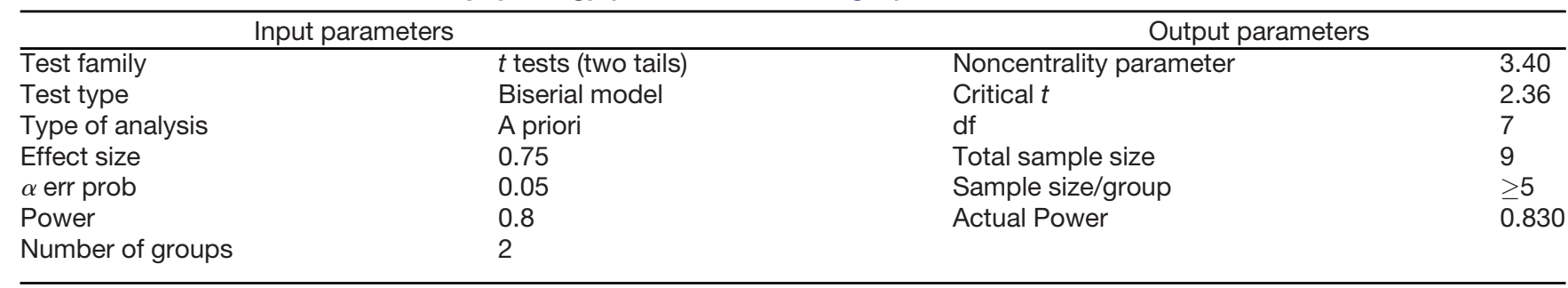

Sample size indicates the number of neurons/cells needed for sufficient power. 


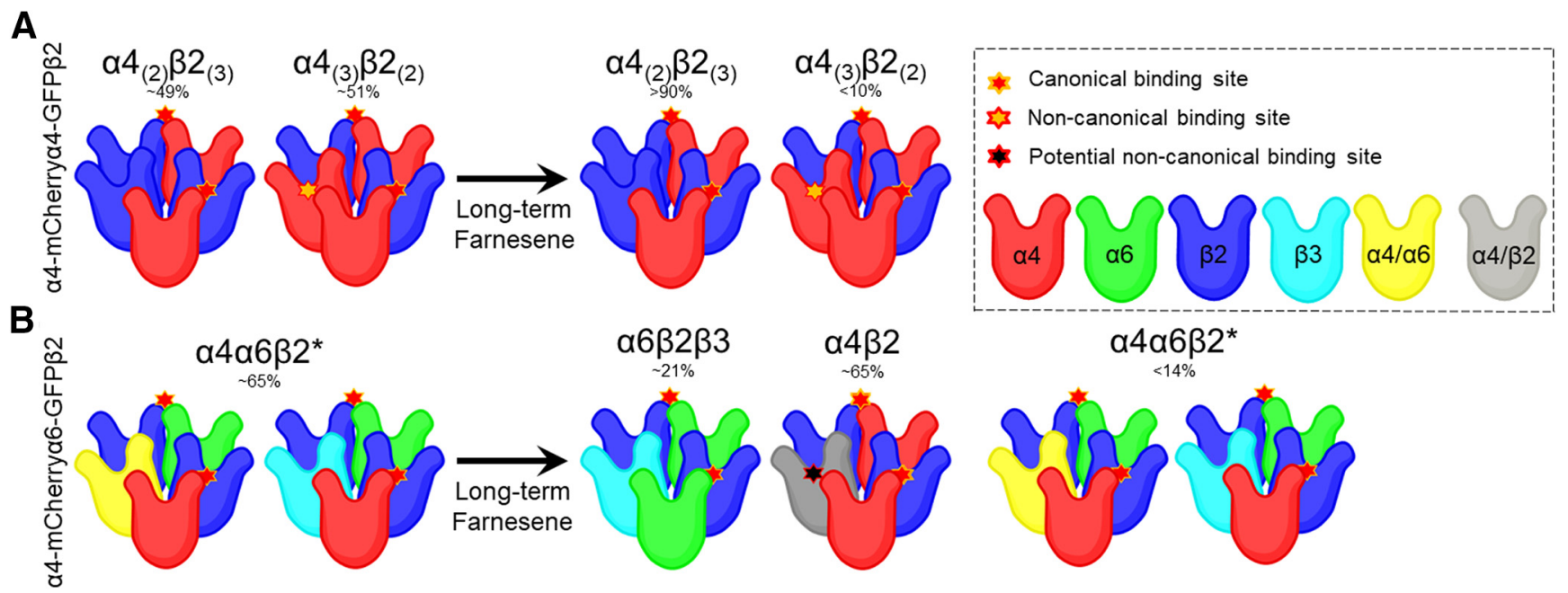

Figure 6. Farnesene favors high-sensitivity nAChRs in neuro-2a cells. $\boldsymbol{A}, \alpha 4 \beta 2 \mathrm{nAChRs}$ assemble in two stoichiometries, and we observed that farnesene treatment shifts a mixed population of HS and LS $\alpha 4 \beta 2 \mathrm{nAChRs}$ to a majority of HS $\alpha 4 \beta 2 \mathrm{nAChRs}$. B, In

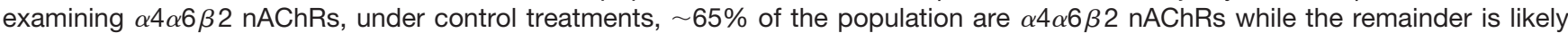
$\alpha 4 \beta 2$ nAChRs. Following treatment with farnesene, $<14 \%$ of the nAChRs are $\alpha 4 \alpha 6 \beta 2$ nAChRs.

robust method of identifying pDA neurons (Mackey et al., 2012; Henderson et al., 2017). We used coronal brain slices obtained from saline or $0.1 \mathrm{mg} / \mathrm{kg}$ farnesene treated mice using a dosing paradigm that matches the above CPP protocol and targeted bregma -3.1 to match confocal microscopy assays. Putative VTA dopamine neurons were voltage-clamped at $-65 \mathrm{mV}$ and $0.5,5,10$, and $100 \mu \mathrm{M}$ concentrations of nicotine were applied using localized pressure injection with a micropipette ( $5 \mathrm{psi}, 10$-s applications; Fig. $\left.7 B_{1,2}, C\right)$. In the farnesene-treated condition, we noted a leftward shift in the concentration response of nicotine, indicative of a shift toward more high-sensitivity nAChRs (Fig. 7C). In addition to recording nicotinestimulated inward currents, we also recorded SEPSCs in pDA neurons (Fig. 7D). Here, we observed that chronic farnesene increased the baseline frequency $(p=0.0163)$ and amplitude $(p<0.0001)$ of SEPSCs on putative VTA dopamine neurons compared with saline treatment (Fig. $\left.7 E_{1,2}\right)$.

\section{Farnesene acts as a partial agonist of nAChRs}

The previous report on farnesol, another green apple flavorant, showed that farnesol did not stimulate nAChRmediated currents on its own but likely functions as a noncompetitive antagonist (Avelar et al., 2019). To examine farnesene's pharmacological actions, we first started with acute applications on putative VTA dopamine neurons (Fig. $8 A, B$ ). We observed that 5 and $500 \mu \mathrm{m}$ farnesene stimulates inward currents in putative VTA dopamine neurons (mean peak current amplitudes of $27.5 \pm 3.3$ and $58.5 \pm 9.6 \mathrm{pA}$, respectively; Fig. $8 B$ ). We note that $0.5 \mu \mathrm{m}$ farnesene (consistent with in vitro NFRET assays) did not produce any notable inward currents (data not shown). Using ACSF containing $\operatorname{Dh} \beta \mathrm{E}(0.3 \mu \mathrm{M})$, we observed that farnesene-induced $(500 \mu \mathrm{M})$ inward currents are dependent on $\beta 2 * \mathrm{nAChRs}$ (Fig. 8A). Finally, we used $100 \mu \mathrm{m}$ nicotine to obtain a comparative efficacy for farnesene and determined that farnesene possessed $\leq 44.0 \pm 7.3 \%$ efficacy compared with nicotine (at $100 \mu \mathrm{M}$ ) on putative VTA dopamine neurons. Five and $500 \mu \mathrm{m}$ farnesene had a significantly lower peak current amplitude compared with $100 \mu \mathrm{m}$ nicotine $(p<0.0001$ and $p<0.0031$, respectively). In examining peak current amplitudes of nAChRs on dopamine neurons, it is difficult to isolate exactly which subtypes are activated. To address this, we used neuro-2a cells transiently transfected to contain either $\alpha 4$ GFP $\beta 2$ or $\alpha 6$-GFP $\beta 2 \beta 3$ nAChRs (Fig. $8 C$ ). These two nAChR subtypes exhibit distinct sensitivities to nicotine and can be maximally stimulated by $3 \mu \mathrm{m}$ nicotine $(\alpha 6-$ GFP $\beta 2 \beta 3$ nAChRs) or 100-300 $\mu \mathrm{m}$ nicotine $(\alpha 4$-GFP $\beta 2$ nAChRs; Henderson et al., 2014). For neuro-2a cells containing nAChRs, we applied $500 \mu \mathrm{m}$ farnesene (300-ms applications) and observed mean peak current amplitudes of $21.2 \pm 3.0$ and $23.8 \pm 6.1 \mathrm{pA}$ for $\alpha 6$-GFP $\beta 2 \beta 3$ and $\alpha 4$-GFP $\beta 2$ nAChRs, respectively (Fig. $8 E_{1,2}$ ). Using 3 and $100 \mu \mathrm{m}$ nicotine, we observed mean peak current amplitudes of $109.7 \pm 14.3 \mathrm{pA}(p<0.0001)$ and $1190.4 \pm$ $192.3 \mathrm{pA}(p<0.0001)$ for $\alpha 6$-GFP $\beta 2 \beta 3$ and $\alpha 4$-GFP $\beta 2$ nAChRs, respectively (Fig. $8 E_{1,2}$ ). Thus, the comparative efficacy of farnesene to nicotine is $19.3 \pm 2.7 \%$ and $2.1 \pm 0.6 \%$ for $\alpha 6$-GFP $\beta 2 \beta 3$ and $\alpha 4$-GFP $\beta 2$ nAChRs, respectively.

\section{Discussion}

With the growing popularity of ENDS products among all ages and the large preference for flavored e-liquids (Schneller et al., 2018; Huang et al., 2019; Mead et al., 2019), the goal of our study was to determine how one green apple flavorant, farnesene, may affect vaping-related behaviors using behavioral, neurobiological, and neurophysiological assays. Menthol has long been the most studied flavorant for its large prevalence in combustible cigarettes and is known to enhance nicotine reward (Henderson et al., 2016, 2017) and nicotine reinforcement (Wang et al., 2014; Biswas et al., 2016). Yet, with the increase in flavorant production with $>15,000$ ENDS 

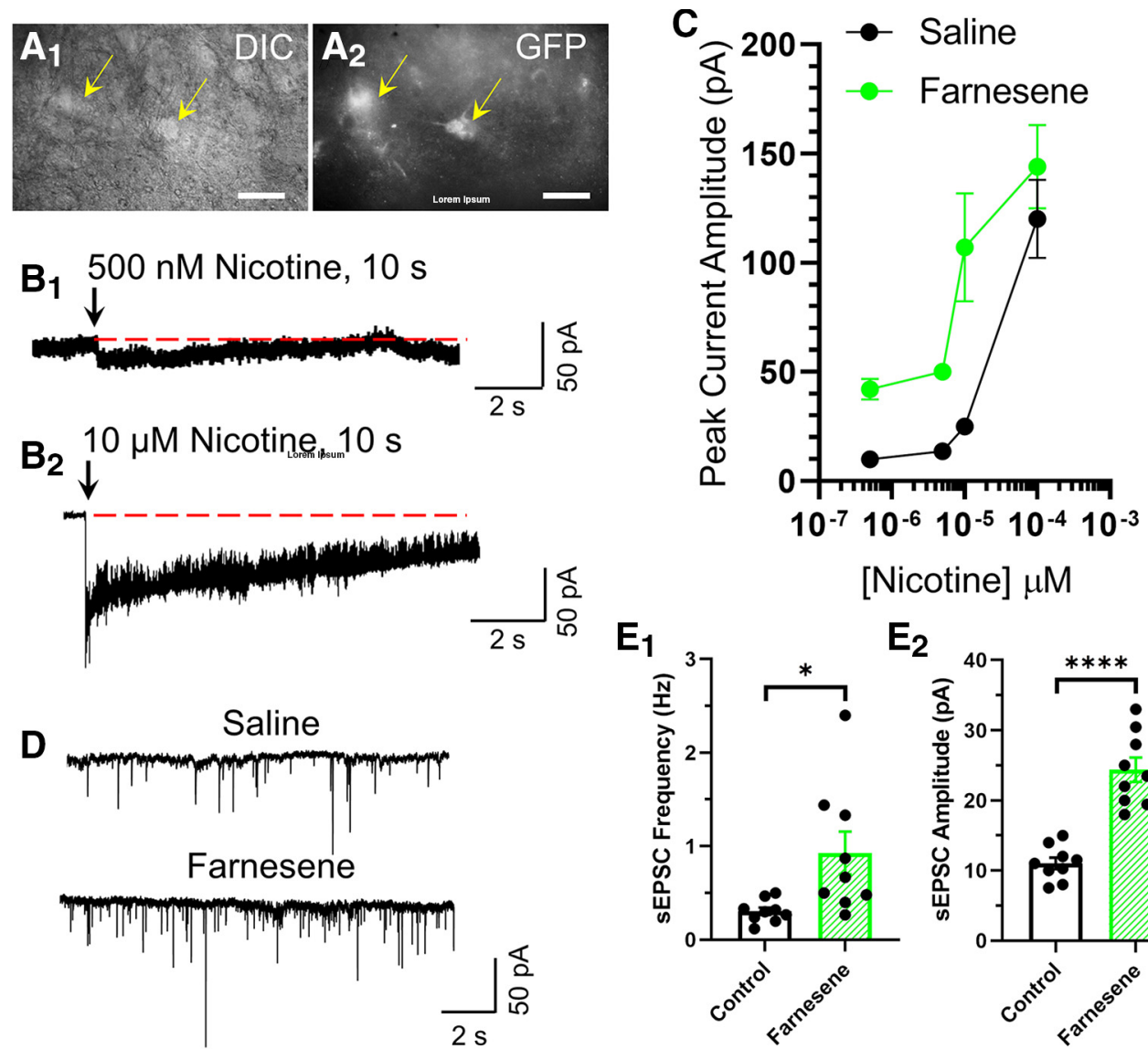

[Nicotine] $\mu \mathrm{M}$
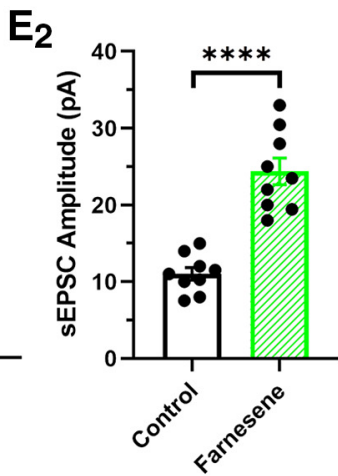

Figure 7. Farnesene enhances the affinity and potency of nicotine. Representative images of VTA pDA neurons in a brain slice (bregma -3.1) were identified through the presence of $\alpha 6$-GFP nAChRs in IR-DIC $\left(\boldsymbol{A}_{1}\right)$ and GFP fluorescence $\left(\boldsymbol{A}_{2}\right)$ imaging modes.

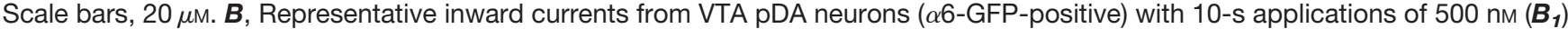
or $10 \mu \mathrm{M}\left(\boldsymbol{B}_{2}\right)$ nicotine in voltage-clamp mode. Arrows indicate start of nicotine puff application and dotted red lines indicate baseline before puff and the duration of nicotine application. $\boldsymbol{C}$, Average nicotine concentration response of peak-current amplitude of VTA pDA neurons ( $n=7$ neurons/4 mice and 5 neurons/3 mice per nicotine concentration for saline-treated and farnesene-treated mice, respectively). $\boldsymbol{D}$, Representative waveforms of SEPSCs from VTA pDA neurons recorded from saline-treated or farnesene-treated mice in the presence of $30 \mu \mathrm{m}$ picrotoxin. $\boldsymbol{E}$, Mean sEPSC frequency $\left(\boldsymbol{E}_{\mathbf{1}}\right)$ and amplitude $\left(\boldsymbol{E}_{2}\right)$ in saline-treated and farnesene-treated mouse brain slices ( $n=9$ neurons $/ 4$ mice and 9 neurons $/ 3$ mice for saline-treated and farnesene-treated mice, respectively). For all assays, drug treatments were consistent with the CPP assay paradigm using $0.1 \mathrm{mg} / \mathrm{kg}$ farnesene. $\boldsymbol{C}, \boldsymbol{E}_{l, 2}$, Data are mean $\pm \mathrm{SEM}$ $* p<0.05, * * * * p<0.0001$; unpaired $t$ test. Exact $p$ values are given in Results. Dots within bars represent the values from individual neurons within the designated treatment group.

flavorant options available to the vaping community (Hsu et al., 2018), there is an urgent need to understand how flavorants alter neurobiology and neurophysiology. A recent investigation revealed farnesol (a green apple flavorant similar in structure to farnesene) behaves similarly to menthol by enhancing nicotine reward but differs in the fact that it causes reward-related behavior on its own (Henderson et al., 2017; Avelar et al., 2019). Here, we noted similar findings: farnesene, a green apple flavorant, causes reward-related behavior on its own. However, one key difference from the previous report is that farnesene produces reward in male and female mice while farnesol only produced an effect with males (Avelar et al., 2019). Additionally, farnesol caused significant upregulation of $\alpha 6$-containing nAChRs (Avelar et al., 2019), but farnesene did not upregulate nAChRs. Instead, farnesene was observed to alter nAChR stoichiometry to promote the expression of more high-sensitivity nAChRs as evidenced by electrophysiology and NFRET assays in mouse brain slices and cultured cells.

This is a very significant finding considering that $>90 \%$ of adolescents ENDS users and $>70 \%$ of adult ENDS users prefer flavored products (Schneller et al., 2018; Mead et al., 2019). Given the absence of restrictions on most flavored ENDS, it is important we document the effects that flavorants have on altering the addictive nature of nicotine and determining potential addictive properties in flavorants alone. Although we observed reward-related behavior with farnesene in both sexes, we did note sex differences in our CPP assays. First, females exhibited reward-related behavior at all doses of farnesene examined $(0.1,1$, and $10 \mathrm{mg} / \mathrm{kg})$ while males exhibited reward to only $0.1 \mathrm{mg} / \mathrm{kg}$ farnesene. This may be because of the fact that females metabolize farnesene faster than males, 

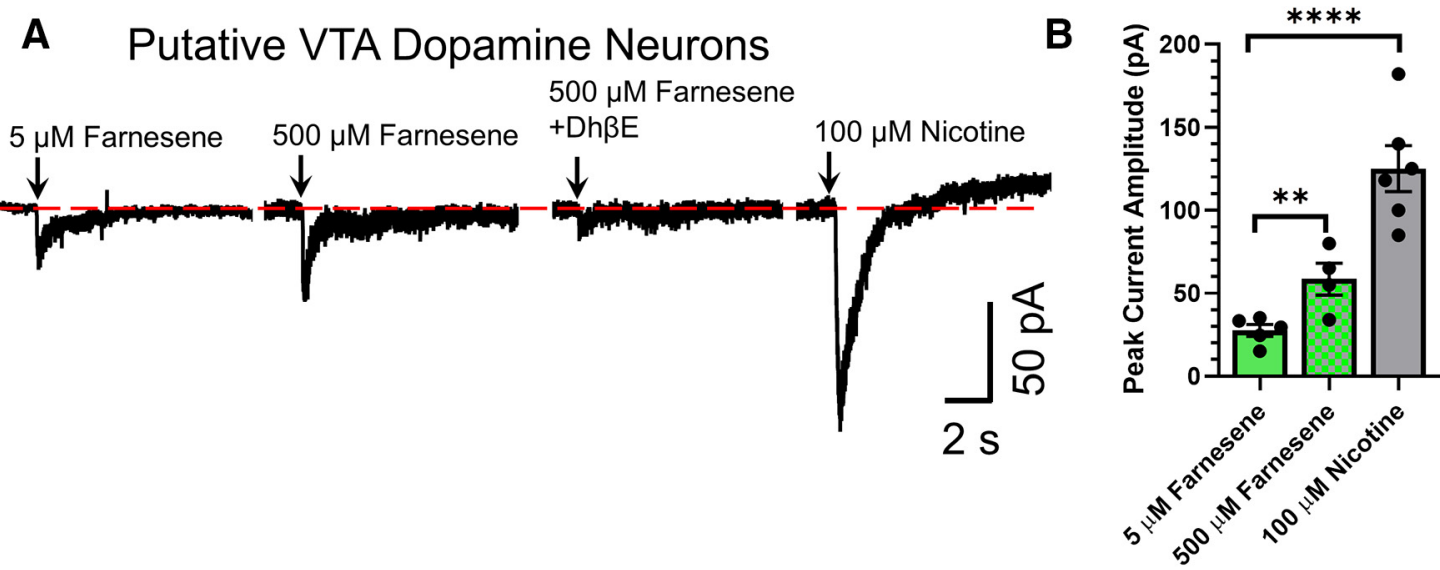

C

D

$E_{1}$

$\mathrm{E}_{2}$

a4-GFP $\beta 2$ nAChRs, Neuro-2a Cells
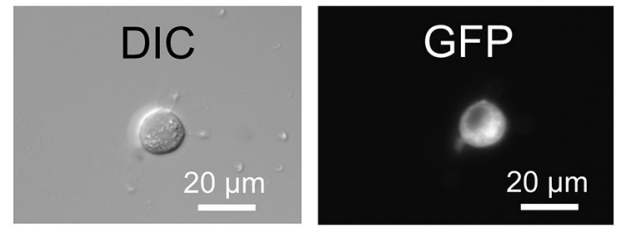

a6-GFP $32 \beta 3$ nAChRs, Neuro-2a Cells
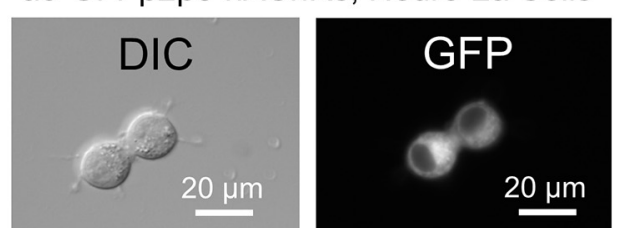

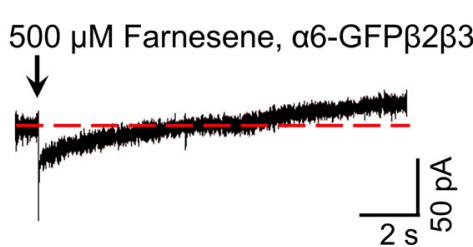

$500 \mu \mathrm{M}$ Farnesene, a4-GFPß2

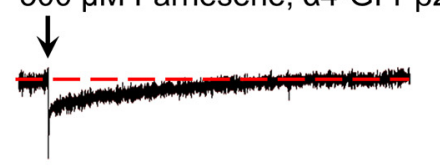

\section{3}

\section{言}
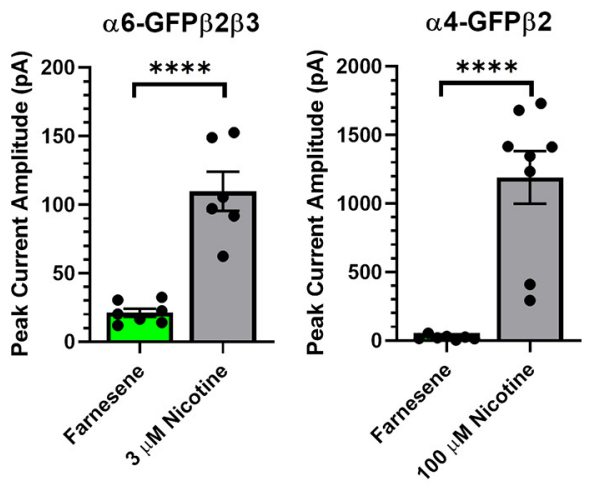

Figure 8. Farnesene acts as a partial agonist on nAChRs. $\boldsymbol{A}, \boldsymbol{B}$, Voltage-clamp recordings from putative VTA dopamine neurons. $\boldsymbol{A}$, Five and $500 \mu \mathrm{m}$ farnesene and $100 \mu \mathrm{m}$ nicotine were applied to putative VTA dopamine neurons. The $\beta 2 * \mathrm{nAChR}$ antagonist, $\operatorname{Dh} \beta \mathrm{E}(0.3 \mu \mathrm{m})$ blocked inward currents stimulated by $500 \mu \mathrm{m}$ farnesene. $\boldsymbol{B}$, Mean peak current amplitude for farnesene and nicotine applications on pDA neurons in the VTA. $\boldsymbol{C}-\boldsymbol{E}$, Voltage-clamp recordings from neuro-2a cells transiently transfected to contain $\alpha 4-$ GFP $\beta 2$ and $\alpha 6$-GFP $\beta 2 \beta 3$ nAChRs. C, Representative images of neuro-2a cells that contain $\alpha 4-G F P \beta 2$ or $\alpha 6$-GFP $\beta 2 \beta 3$ nAChRs. $\boldsymbol{D}$, Representative inward currents stimulated by 300 -ms applications of $500 \mu \mathrm{m}$ farnesene on neuro-2a cells containing $\alpha 4-\mathrm{GFP} \beta 2$ or $\alpha 6$-GFP $\beta 2 \beta 3$ nAChRs. $\boldsymbol{E}_{\mathbf{1 , 2}}$, Mean peak current amplitude of $500 \mu \mathrm{m}$ farnesene and nicotine applications (3 and $100 \mu \mathrm{m}$ nicotine for $\alpha 6$-GFP $\beta 2 \beta 3$ and $\alpha 4$-GFP $\beta 2$ nAChRs, respectively) on neuro-2a cells containing nAChRs. $\boldsymbol{B}, \boldsymbol{E}_{\boldsymbol{1}, 2}$, Data are mean \pm SEM; $* * p<0.01, * * * * p<0.0001$; one-way ANOVA with post hoc Tukey $(\boldsymbol{B})$ or unpaired $t$ test $(\boldsymbol{E})$. Dots represent data from individual neurons or cells. Exact $p$ values are given in Results.

similar to nicotine (Matta et al., 2007). Additionally, females did not exhibit significant nicotine reward with $0.5 \mathrm{mg} / \mathrm{kg}$ nicotine. To date, nicotine dose-response data have primarily been in male mice, and those in females are only given via subcutaneous injection (Kota et al., 2008). Because of the lack of nicotine dose-response curve data using intraperitoneal injections in females, this may explain the lack of significant nicotine reward at the given dose. Although there is a significant change from baseline for nicotine + farnesene in both males and females, the change from baseline is less than farnesenealone in both sexes. While others have reported significant CPP with $0.5 \mathrm{mg} / \mathrm{kg}$ nicotine in CPP assays using both sexes, this could highlight the need to re-examine nicotine dose responses with both sexes in this assay. Additionally, we would like to note that acute farnesene did not significantly alter locomotor behavior compared with saline treatment in male or female mice. Although nicotine and farnesol were observed to increase locomotor activity in mice, previous studies have demonstrated these changes are likely mediated through $\alpha 6 \beta 2 *$ and $\alpha 4 \alpha 6 \beta 2 *$ nAChRs (Drenan et al., 2010; Cohen et al., 2012). Given that the farnesene-induced behavioral effects shown here are likely mediated through high-sensitivity $\alpha 4 \beta 2 \mathrm{nAChRs}$, this may be the reason we did not see any significant changes in locomotor behavior between farnesene-treated or saline-treated mice.

Although farnesol and farnesene exhibit similar behavioral results, they differ in the cellular aspects that drive reward-related behavior. Based on previously published findings that chronic nicotine exposure promotes the upregulation of high-sensitivity nAChRs on VTA dopamine, VTA/SNr GABA, and habenular neurons and the recent evidence that farnesol acted in a similar manner, our initial 
investigations focused on the number of $\alpha 4 *, \alpha 6 *$, and $\alpha 4 \alpha 6 *$ nAChRs present on dopamine and GABA neurons as a consequence of farnesene exposure. We noted no significant changes between farnesene and saline treatment groups. The reward-related behaviors we noted may not be attributed to $n A C h R$ upregulation but, instead, by changes in $\mathrm{nAChR}$ stoichiometry. While many are well informed regarding the various subtypes of nAChRs, there also exist distinct stoichiometries that confer different sensitivities to nicotine (Nelson et al., 2003; Tapia et al., 2007). Both our microscopy measurements (NFRET) and brain slice electrophysiology data support the fact that farnesene treatment, consistent with CPP dosing, produces more high-sensitivity nAChRs on VTA dopamine neurons. This increase in high-sensitivity (likely $\alpha 4 \beta 2$ ) nAChRs results in not only increased sensitivity to nicotine, but also to the endogenous neurotransmitter ACh.

In the case of changes in stoichiometry, we note there are limitations to our methods. Currently, we possess only the capability to measure $\alpha 4 \alpha 6 * \mathrm{nAChR}$ stoichiometry in vivo. Thus, we required the use of heterologous cells and transfection methods in an in vitro system to conduct fluorescence microscopy assays to study changes in $\alpha 4 \beta 2$ nAChR stoichiometry. We acknowledge that this may not truly represent in vivo systems and we note a distinct difference between the in vivo and in vitro findings with $\alpha 4 \alpha 6 *$ nAChRs (compare Figs. $4,5 B_{1,2}$ ). These two systems also differ in the time dependency of nAChR upregulation and stoichiometry changes. Nicotine or flavorant induced $\mathrm{nAChR}$ upregulation and changes in stoichiometry occur over the course of 10-12 d in vivo (Henderson et al., 2016, 2017; Nashmi et al., 2007), whereas the in vitro system findings occur in $24 \mathrm{~h}$ (Srinivasan et al., 2011). This difference in time dependency for in vitro preparations is accompanied by the lacking complexity of a cell's environment in vivo (Fu et al., 2019). Stoichiometry changes within in vivo systems are not only brain region specific (Fu et al., 2019), but they also rely on unique cellular machinery that is absent in our in vitro model. Despite this, our transfection methods follow validated protocols that have matched several in vivo mouse and human studies (Srinivasan et al., 2011; Henderson et al., 2017), and we are able to detect a change in nAChR stoichiometry that is consistent with our findings using brain slice electrophysiology as both suggest the presence of more high-affinity nAChRs.

Farnesene treatment significantly increased the frequency and amplitude of sEPSCs. The excitatory inputs to the VTA dopamine neurons we studied are local and distal glutamate neurons (medial VTA, prefrontal cortex) and distal cholinergic neurons (peduncular pontine tegmentum and laterodorsal tegmentum). The inhibitory inputs are GABA neurons in the VTA, rostromedial tegmentum, and interpeduncular nucleus. Thus, the changes in SEPSC frequency and amplitude are likely because of changes in glutamatergic or GABAergic local inputs given that we used a coronal brain slice preparation. While many of the cholinergic inputs are distal and are not present in a coronal slice preparation, some cholinergic signaling is maintained, and this is likely a source of elevated
sEPSC frequency and amplitude. Regardless, the enhanced frequency and amplitude of sEPSCs in VTA dopamine neurons suggests that farnesene triggers enhanced activity that may drive dopamine release through the mesolimbic pathway and thus contribute to reward-related behavior.

In addition to this, we observed that farnesene itself acts as a partial agonist, likely through $\alpha 6$-containing nAChRs, as it exhibited very low efficacy on $\alpha 4 \beta 2 \mathrm{nAChRs}$ transiently transfected into neuro-2a cells. Here, we must acknowledge that a dose of $500 \mu \mathrm{m}$ is likely not vaping relevant, but it was necessary to determine the comparable efficacy to nicotine. Despite this, $5 \mu \mathrm{m}$ farnesene still produced detectable inward currents in VTA dopamine neurons, and this suggests that farnesene may also weakly stimulate nAChRs in the VTA. Here, further investigations would need to be conducted to determine the human vaping-relevant concentrations of farnesene that would be present in the brain and how this specific concentration alters neurophysiology. Even with these caveats, this finding is significant, especially in the rising popularity of zero-nicotine e-liquids. Green apple flavors (depending on the specific flavorants present) may directly stimulate $\mathrm{nAChRs}$, and this could be the rationale for their popularity.

The data reported in this study suggest that (1) farnesene enhances nicotine reward and displays reward-related behavior through the increase in high-sensitivity nAChRs on VTA dopaminergic neurons; (2) that farnesene changes $\mathrm{nAChR}$ stoichiometry and results in an enhanced affinity and potency of nicotine and ACh; and (3) that this ultimately leads to enhanced excitatory postsynaptic currents on VTA dopamine neurons and thus greater likelihood of action potential generation. Overall, this may explain why flavored ENDS are growing in popularity and may contribute to low cessation rates. The finding of enhanced nicotine reward when flavorants are present and the fact that flavorants-alone may be rewarding, further indicates the importance of studying flavorants for their potential to alter vaping-related behaviors. However, there are components of this local VTA circuitry that still need to be elucidated: (1) how are VTA glutamatergic inputs and their nAChRs altered by farnesene; (2) how are $\alpha 4 \beta 2 \mathrm{nAChRs}$ on VTA GABA neurons altered functionally; and (3) what is the net effect of farnesene on dopamine release. Additionally, there are several green apple flavorants that are still unknowns in the scope of how they alter vaping-related behavior (methylbutyl acetate, hexyl acetate, and ethyl acetate). Based on these findings, it is of importance we continue to investigate ENDS flavors for their role in nicotine addiction. With the continuous rise in ENDS use, especially among the adolescent population, it is critical we depict that ENDS flavors are not a simple additive to the devices, instead they are an enhancer to the addictive properties of nicotine and a potential threat to zero-nicotine flavored ENDS users as well.

\section{References}

Avelar AJ, Akers AT, Baumgard ZJ, Cooper SY, Casinelli GP, Henderson BJ (2019) Why flavored vape products may be attractive: green apple tobacco flavor elicits reward-related behavior, 
upregulates nAChRs on VTA dopamine neurons, and alters midbrain dopamine and GABA neuron function. Neuropharmacology 158:107729.

Biswas L, Harrison E, Gong Y, Avusula R, Lee J, Zhang M, Rousselle T, Lage J, Liu X (2016) Enhancing effect of menthol on nicotine self-administration in rats. Psychopharmacology (Berl) 233:34173427.

Brody A, Mukhin A, La Charite J, Ta K, Farahi J, Sugar C, Mamoun M, Vellios E, Archie M, Kozman M, Phuong J, Arlorio F, Mandelkern M (2013) Up-regulation of nicotinic acetylcholine receptors in menthol cigarette smokers. Int J Neuropsychopharmacol 16:957-966.

Cohen BN, Mackey ED, Grady SR, McKinney S, Patzlaff NE, Wageman CR, Mclntosh JM, Marks MJ, Lester HA, Drenan RM (2012) Nicotinic cholinergic mechanisms causing elevated dopamine release and abnormal locomotor behavior. Neuroscience 200:31-41.

Cullen KA, Ambrose BK, Gentzke AS, Apelberg BJ, Jamal A, King BA (2018) Notes from the field: use of electronic cigarettes and any tobacco product among middle and high school students - United States, 2011-2018. MMWR Morb Mortal Wkly Rep 67:1276-1277.

Cullen KA, Liu ST, Bernat JK, Slavit WI, Tynan MA, King BA, Neff LJ (2019) Flavored tobacco product use among middle and high school students-United States, 2014-2018. MMWR Morb Mortal Wkly Rep 68:839-844.

Drenan RM, Grady SR, Steele AD, McKinney S, Patzlaff NE, Mclntosh JM, Marks MJ, Miwa JM, Lester HA (2010) Cholinergic modulation of locomotion and striatal dopamine release is mediated by alpha6alpha4* nicotinic acetylcholine receptors. J Neurosci 30:9877-9889.

Einstein EB, Asaka Y, Yeckel MF, Higley MJ, Picciotto MR (2013) Galanin-induced decreases in nucleus accumbens/striatum excitatory postsynaptic potentials and morphine conditioned place preference require both galanin receptor 1 and galanin receptor 2 . Eur J Neurosci 37:1541-1549.

Espino-Díaz M, Sepúlveda DR, González-Aguilar G, Olivas GI (2016) Biochemistry of apple aroma: a review. Food Technol Biotechnol 54:375-397.

Fan L, Balakrishna S, Jabba SV, Bonner PE, Taylor SR, Picciotto MR, Jordt SE (2016) Menthol decreases oral nicotine aversion in C57BL/6 mice through a TRPM8-dependent mechanism. Tob Control 25:ii50- ii55.

FDA (2018) Statement from FDA Commissioner Scott Gottlieb, M.D., on new steps to address epidemic of youth e-cigarette use. US Department of Health and Human Services. Available at https://www. fda.gov/NewsEvents/Newsroom/PressAnnouncements/ucm620185. htm.

Fu X, Moonschi FH, Fox-Loe AM, Snell AA, Hopkins DM, Avelar AJ, Henderson BJ, Pauly JR, Richards CI (2019) Brain region specific single-molecule fluorescence imaging. Anal Chem 91:1012510131.

Henderson BJ, Srinivasan R, Nichols WA, Dilworth CN, Gutierrez DF, Mackey ED, McKinney S, Drenan RM, Richards Cl, Lester HA (2014) Nicotine exploits a COPI-mediated process for chaperonemediated up-regulation of its receptors. J Gen Physiol 143:51-66.

Henderson BJ, Wall T, Henley BM, Kim CH, Nichols WA, Moaddel R, Xiao C, Lester HA (2016) Menthol alone upregulates midbrain $\mathrm{nAChRs}$, alters nAChR sybtype stoichiometry, alters dopamine neuron firing frequency, and prevents nicotine reward. J Neurosci 36:2957-2974.

Henderson BJ, Wall TR, Henley BM, Kim CH, McKinney S, Lester HA (2017) Menthol enhances nicotine reward-related behavior by potentiating nicotine-induced changes in $\mathrm{nAChR}$ function, $\mathrm{nAChR}$ upregulation, and DA neuron excitability. Neuropsychopharmacology 42:2285-2291.

Henderson BJ, Grant S, Chu BW ,Wong BK, Shahoei R, Huard SM, Saladi SSM, Tajkhorshid E, Dougherty DA, Lester HA (2018) Menthol stereoisomers exhibit different effects on $\alpha 4 \beta 2$ nAChR upregulation and dopamine neuron spontaneous firing. eNeuro 5 : e0465-18.
Hsu G, Sun JY, Zhu SH (2018) Evolution of electronic cigarette brands from 2013-2014 to 2016-2017: analysis of brand websites. J Med Internet Res 20:e80.

Huang J, Duan Z, Kwok J, Binns S, Vera LE, Kim Y, Szczypka G, Emery SL (2019) Vaping versus JUULing: how the extraordinary growth and marketing of JUUL transformed the US retail e-cigarette market. Tob Control 28:146-151.

Kota D, Martin BR, Damaj MI (2008) Age-dependent differences in nicotine reward and withdrawal in female mice. Psychopharmacology (Berl) 198:201-210.

Kuryatov A, Luo J, Cooper J, Lindstrom J (2005) Nicotine acts as a pharmacological chaperone to up-regulate human alpha4beta2 acetylcholine receptors. Mol Pharmacol 68:1839-1851.

Lee AM, Calarco CA, McKee SA, Mineur YS, Picciotto MR (2020) Variability in nicotine conditioned place preference and stress-induced reinstatement in mice: effects of sex, initial chamber preference, and guanfacine. Genes Brain Behav 19:e12601.

Lindstrom J, Schoepfer R, Whiting P (1987) Molecular studies of the neuronal nicotinic acetylcholine receptor family. Mol Neurobiol 1:281-337.

Mackey ED, Engle SE, Kim MR, O'Neill HC, Wageman CR, Patzlaff NE, Wang Y, Grady SR, Mclntosh JM, Marks MJ, Lester HA, Drenan RM (2012) $\alpha 6 *$ nicotinic acetylcholine receptor expression and function in a visual salience circuit. J Neurosci 32:1022610237.

Margolis EB, Lock H, Hjelmstad GO, Fields HL (2006) The ventral tegmental area revisited: is there an electrophysiological marker for dopaminergic neurons? J Physiol 577:907-924.

Margolis EB, Mitchell JM, Ishikawa J, Hjelmstad GO, Fields HL (2008) Midbrain dopamine neurons: projection target determines action potential duration and dopamine $\mathrm{D}(2)$ receptor inhibition. J Neurosci 28:8908-8913.

Matta SG, Balfour DJ, Benowitz NL, Boyd RT, Buccafusco JJ, Caggiula AR, Craig CR, Collins AC, Damaj MI, Donny EC, Gardiner PS, Grady SR, Heberlein U, Leonard SS, Levin ED, Lukas RJ, Markou A, Marks MJ, McCallum SE, Parameswaran N, et al. (2007) Guidelines on nicotine dose selection for in vivo research. Psychopharmacology (Berl) 190:269-319.

Mead EL, Duffy V, Oncken C, Litt MD (2019) E-cigarette palatability in smokers as a function of flavorings, nicotine content and propylthiouracil (PROP) taster phenotype. Addict Behav 91:37-44.

Nashmi R, Dickinson ME, McKinney S, Jareb M, Labarca C, Fraser SE, Lester HA (2003) Assembly of $\alpha 4 \beta 2$ nicotinic acetylcholine receptors assessed with functional fluorescently labeled subunits: effects of localization, trafficking, and nicotine-induced upregulation in clonal mammalian cells and in cultured midbrain neurons. $J$ Neurosci 23:11554-11567.

Nashmi R, Xiao C, Deshpande P, McKinney S, Grady SR, Whiteaker P, Huang Q, McClure-Begley T, Lindstrom JM, Labarca C, Collins AC, Marks MJ, Lester HA (2007) Chronic nicotine cell specifically upregulates functional alpha $4 *$ nicotinic receptors: basis for both tolerance in midbrain and enhanced long-term potentiation in perforant path. J Neurosci 27:8202-8218.

Nelson ME, Kuryatov A, Choi CH, Zhou Y, Lindstrom J (2003) Alternate stoichiometries of alpha4beta2 nicotinic acetylcholine receptors. Mol Pharmacol 63:332-341.

Neugebauer NM, Henehan RM, Hales CA, Picciotto MR (2011) Mice lacking the galanin gene show decreased sensitivity to nicotine conditioned place preference. Pharmacol Biochem Behav 98:8793.

Omaiye EE, McWhirter KJ, Luo W, Tierney PA, Pankow JF, Talbot P (2019) High concentrations of flavor chemicals are present in electronic cigarette refill fluids. Sci Rep 9:2468.

Schneller LM, Bansal-Travers M, Goniewicz ML, McIntosh S, Ossip D, O'Connor RJ (2018) Use of flavored electronic cigarette refill liquids among adults and youth in the US-results from wave 2 of the population assessment of tobacco and health study (20142015). PloS One 13:e0202744.

Srinivasan R, Pantoja R, Moss FJ, Mackey EDW, Son C, Miwa J, Lester HA (2011) Nicotine up-regulates alpha4beta2 nicotinic 
receptors and ER exit sites via stoichiometry-dependent chaperoning. J Gen Physiol 137:59-79.

Srinivasan R, Richards Cl, Dilworth C, Moss FJ, Dougherty DA, Lester HA (2012) Förster resonance energy transfer (FRET) correlates of altered subunit stoichiometry in cys-loop receptors, exemplified by nicotinic $\alpha 4 \beta 2$. Int J Mol Sci 13:10022-10040.

Srinivasan R, Henley BM, Henderson BJ, Indersmitten T, Cohen BN, Kim CH, McKinney s, Deshpande P, Xiao C, Lester HA (2016) Smoking-relevant nicotine concentration attenuates the unfolded protein response in dopaminergic neurons. J Neurosci 36:65-79.

Tapia L, Kuryatov A, Lindstrom J (2007) $\mathrm{Ca}^{2+}$ permeability of the (alpha4 $)_{3}(\text { beta2 })_{2}$ stoichiometry greatly exceeds that of (alpha4) $)_{2}(-$ beta2) ${ }_{3}$ human acetylcholine receptors. Mol Pharmacol 71:769776.

Tapper AR, McKinney SL, Nashmi R, Schwarz J, Deshpande P, Labarca C, Whiteaker P, Marks MJ, Collins AC, Lester HA (2004) Nicotine activation of alpha $4 *$ receptors: sufficient for reward, tolerance, and sensitization. Science 306:1029-1032.

Tierney PA, Karpinski CD, Brown JE, Luo W, Pankow JF (2016) Flavour chemicals in electronic cigarette fluids. Tob Control 25: e10-e15.
Wall TR, Henderson BJ, Voren G, Wageman CR, Deshpande P, Cohen BN, Grady SR, Marks MJ, Yohannes D, Bencherif M, Kenny PJ, Lester HA (2017) TC299423, a novel agonist for nicotinic acetylcholine receptors. Front Pharmacol 8:641.

Wang T, Wang B, Chen H (2014) Menthol facilitates the intravenous self-administration of nicotine in rats. Front Behav Neurosci 8:437.

Xiao C, Nashmi R, McKinney S, Cai H, Mclntosh JM, Lester HA (2009) Chronic nicotine selectively enhances alpha4beta2* nicotinic acetylcholine receptors in the nigrostriatal dopamine pathway. J Neurosci 29:12428-12439.

Xiao C, Srinivasan R, Drenan RM, Mackey ED, Mclntosh JM, Lester HA (2011) Characterizing functional $\alpha 6 \beta 2$ nicotinic acetylcholine receptors in vitro: mutant $\beta 2$ subunits improve membrane expression, and fluorescent proteins reveal responsive cells. Biochem Pharmacol 82:852-861.

Yan Y, Peng C, Arvin MC, Jin XT, Kim VJ, Ramsey MD, Wang Y, Banala S, Wokosin DL, Mclntosh JM, Lavis LD, Drenan RM (2018) Nicotinic cholinergic receptors in VTA glutamate neurons modulate excitatory transmission. Cell Rep 23:2236-2244.

Zhang M, Harrison E, Biswas L, Tran T, Liu X (2018) Menthol facilitates dopamine-releasing effect of nicotine in rat nucleus accumbens. Pharmacol Biochem Behav 175:47-52. 